\title{
Enhancement of the SPARC90 code to pool scrubbing events under jet injection regime
}

\author{
C. Berna ${ }^{1}$, A. Escrivá ${ }^{1}$, J.L. Muñoz-Cobo ${ }^{1}$, Luis E. Herranz ${ }^{2}$ \\ ${ }^{1}$ Instituto de Ingeniería Energética \\ Universitat Politècnica de València (UPV) \\ Camino de Vera 14, 46022 Valencia (Spain)
}

Tel:0034.963879245,Email: ceberes@iie.upv.es

${ }^{2}$ Unit of Nuclear Safety Research

Division of Nuclear Fission, CIEMAT

Avda. Complutense 22, 28040 Madrid (Spain)

Tel: 0034.913466219, Fax:0034.913466233, Email: luisen.herranz@ciemat.es

\begin{abstract}
Submerged gaseous jets may have an outstanding relevance in many industrial processes and may be of particular significance in severe nuclear accident scenarios, like in the Fukushima accident. Even though pool scrubbing has been traditionally associated with low injection velocities, there are a number of potential scenarios in which fission product trapping in aqueous ponds might also occur under jet injection regime (like SGTR meltdown sequences in PWRs and SBO ones in BWRs).
\end{abstract}

The SPARC90 code was developed to determine the fission product trapping in pools during severe accidents. The code assumes that carrier gas arrives at the water ponds at low or moderate velocities and it forms a big bubble that eventually detaches from the injection pipe. However, particle laden gases may enter the water at very high velocities resulting in a submerged gas jet instead.

This work presents the fundamentals, major hypotheses and changes introduced into the code in order to estimate particle removal during gas injection in pools under the jet regime (SPARC90-Jet). A simplified and reliable approach to submerged jet hydrodynamics has been implemented on the basis of updated equations for jet hydrodynamics and aerosol removal, so that gasliquid and droplet-particles interactions are described.

The code modifications have been validated as far as possible. However, no suitable hydrodynamic tests have been found in the literature, so that an indirect validation has been conducted through comparisons against data from pool scrubbing experiments. Besides, this validation has been forcefully limited since very few pool scrubbing tests are available in the jet injection regime (i.e., ACE, LACE, POSEIDON II and RCA). But nevertheless, a considerable improvement in the estimation of the Decontamination Factor (DF) has been reached, as well as it has been proven that sizes of aerosol particles and submergencies are factors of major influence, however there is still a long road ahead.

We have extended the SPARC90 capabilities to study jet discharge processes, then the new SPARC90-Jet version is able to study globular and jet discharge processes, i.e. pool discharges under low and high velocity conditions. 
Therefore, the work here presented should be understood as a promising first step towards an effective code extension to the jet regime.

Keywords: submerged jet, entrainment, pool scrubbing, aerosol capture, severe accident

\section{INTRODUCTION}

Aerosols carried by a gas stream can be removed by the discharge into a liquid volume, this process is usually called scrubbing. In a hypothetical severe accident in a LWR, particle fission products may escape from the core and be transported through the primary system and finally may be released to the surrounding environment. If a water pool exists in the aerosol pathway, either a suppression pool or secondary side of a SG, the aerosol retention will be enhanced. Although pool scrubbing has been traditionally associated with fission product retention in suppression pools of BWR during SBO's events, Figure 1a, there also exits a number of potential scenarios in PWR, in which fission product trapping in aqueous ponds may play a key role in the attenuation of source term. This is the case of SGTR core meltdown sequences, Figure $1 \mathrm{~b}$.
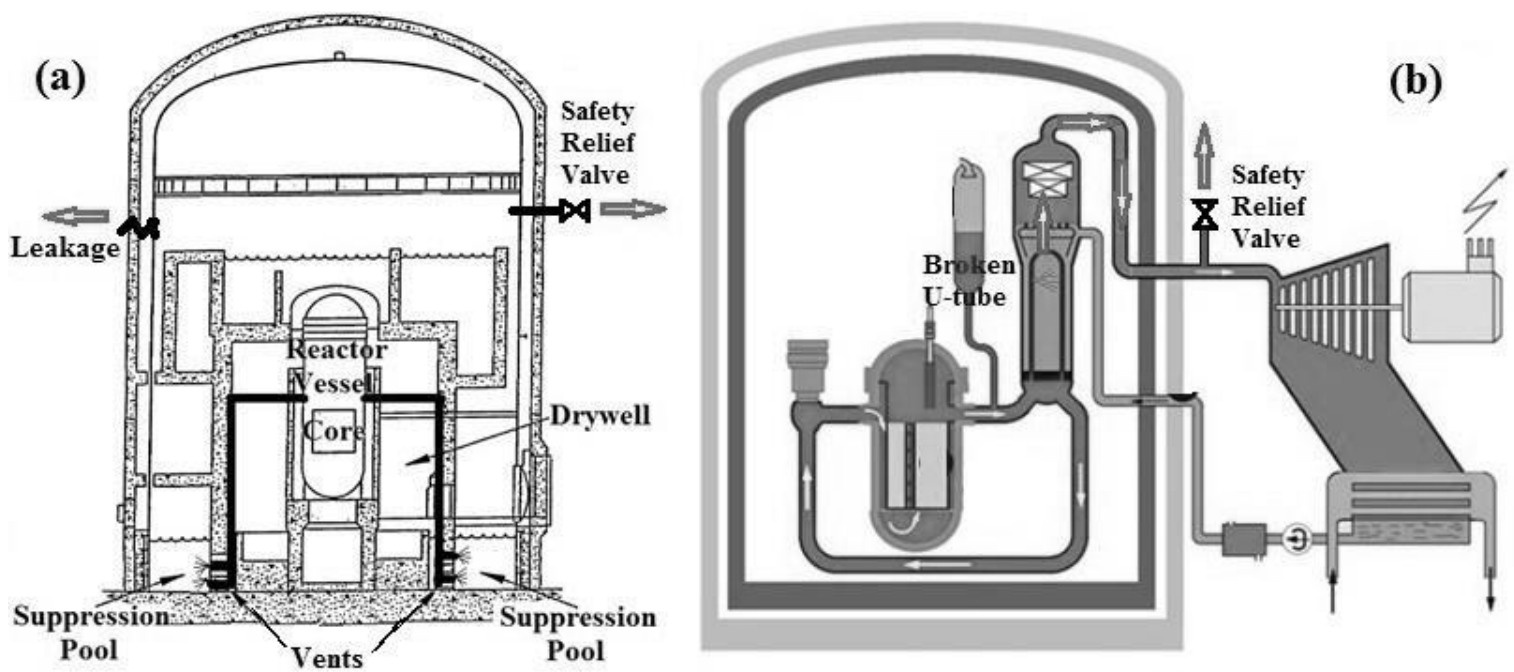

Figure 1. Pathway of the fission products from the core to the environment: (a) BWR; (b) PWR

Retention in aqueous ponds was heavily investigated in the 80's and computation tools, like the codes SUPRA (Wassel, 1985), BUSCA (Ramsdale, 1991) and SPARC (Owczarski, 1991), were developed. Straight application of these tools to high gas injection velocities, though, is not suitable since anticipated gas-liquid and droplets-particles interactions are drastically different.

This work is a step ahead of the recent attempts of our research group towards extending the SPARC90 code to the jet injection regime (Berna, 2012; Herranz, 2013; Berna 2015a). The current SPARC90-Jet code shows several improvements compared to the immediately preceding reported works. In particular, some aspects of the hydrodynamic models (sizes of the entrained droplets, entrainment-deposition balance, etc.) and with regard to the aerosols capture mechanisms (testing and implementation of new expressions), have been improved. The final objective will be to stablish comparisons against data from experiments dealing with the decontamination capability of aqueous ponds 
under representative severe nuclear accident conditions, in particular pool scrubbing and SGTR events.

The previously commented codes related with particle retention in aqueous ponds were not intended to the study of high velocity discharge processes. In particular, the old SPARC90 code modeled gas injection processes under globular regime, i.e., low velocity discharges (Figure 2a). This paper summarizes the SPARC90 code extension to the jet injection regime, SPARC90-Jet (Figure 2b). Under this regime the entrained droplets into the gas core might interact with aerosol particles and, eventually, remove them from the gas and return them into the continuous water phase. This paper discusses the new aspects of these types of discharges and enters the expressions related with the entrained droplets, both aspects which were not covered by the previous code version. Characteristic equations of submerged gas jets have been implemented in the code for variables such as entrainment rate, drop size and velocity, etc. As very few data have been produced in the area of gas jets in aqueous ponds, many of the expressions chosen have been taken from the annular two-phase flow regime. Particle removal equations for dominant mechanisms (i.e., inertial impaction, interception and Brownian diffusion) have been included based on the new hydrodynamic description of the gas, these expressions came from scrubbers due to its similarities with submerged jets.

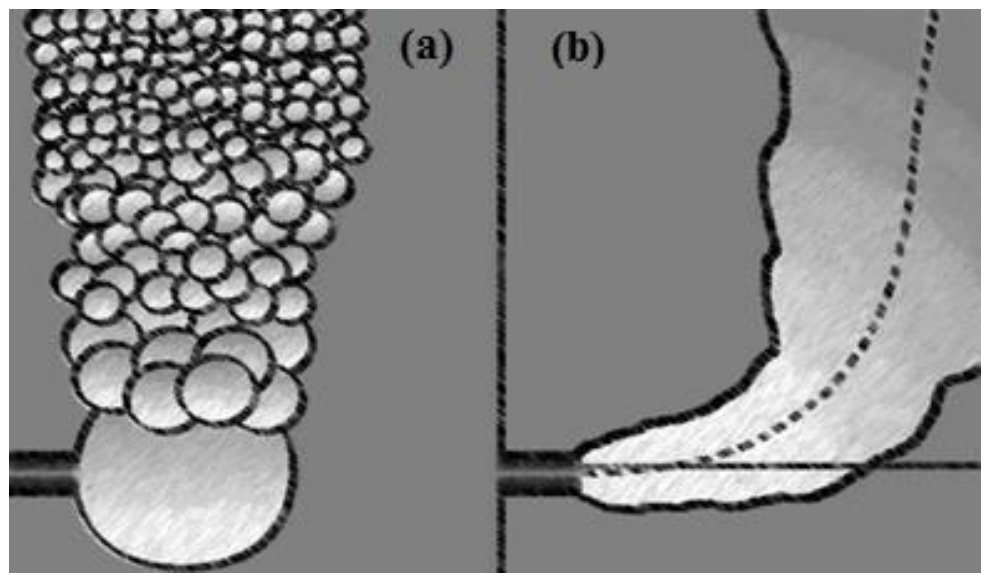

Figure 2. Schematic View of the two existing conceptual approaches: (a) Globular Regime; (b) Jet Injection Regime

Finally, SPARC90-Jet performance has been checked through modeling conditions of pool scrubbing experimental scenarios. These validation processes have been carried out by comparing SPARC90-Jet results against the limited available data of pool scrubbing, concretely the experimental series of the ACE, LACE, POSEIDON II and RCA programs in which injection regime is reached and only non-condensable gases are injected (or only with small amount of steam). This comparison versus experimental data shows promising results, since in all cases the code captures the experimental trends and is near the expected values.

Summarizing, the structure of this paper is as follows, in the first place, the jet hydrodynamics has been developed, after this development, the document continues with the main droplet capture mechanisms. The work continues with the validation tasks of the SPARC90-Jet results against a database of pool 
scrubbing experiments. Finally, a section containing the final remarks and further work has been included.

\section{JET HYDRODYNAMICS}

A submerged gas jet is divided in three zones (Figure 3): an initial expansion (gas and pool pressures match each other); a flow establishment region (central velocity in the potential core remains unchanged); and, a fully developed region (potential core vanishes and central jet velocity decreases).

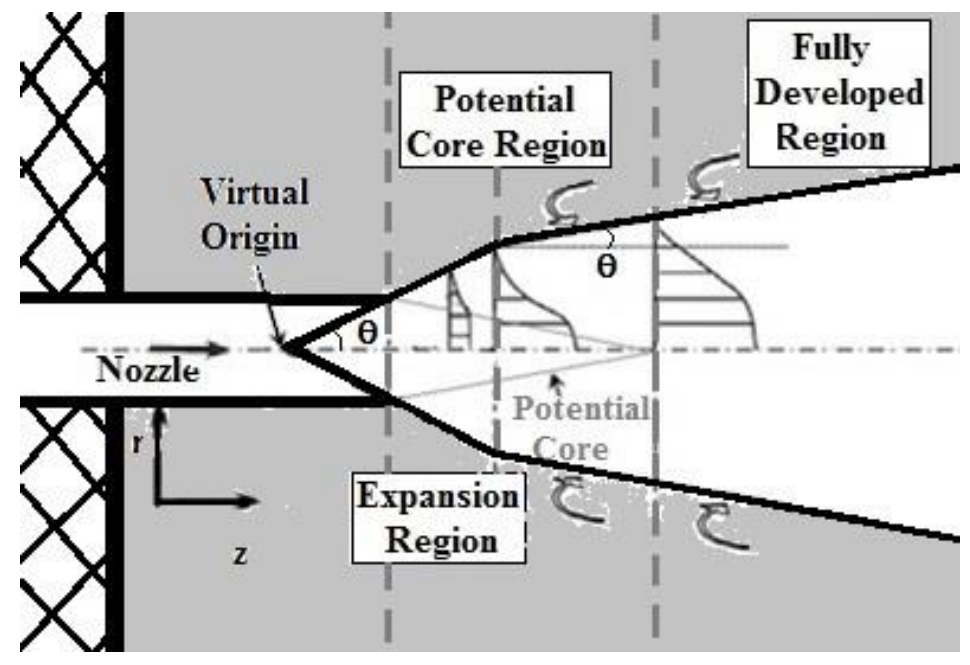

Figure 3.Schematic view of a submerged gas jet

\subsection{General Gas Jet Characteristics}

The main jet features are here introduced: the jet expansion and developed angle, the end of the expansion zone and the initial jet velocity.

\subsubsection{THE EXPANSION ANGLE}

Someya et al. (Someya, 2011) investigated submerged gas jets. They found that in a jet discharge a large expansion occurred rapidly and extended about $3 \mathrm{~mm}$ from the nozzle exit; after this position the expansion progressed at a slower rate, that is, with a narrower angle. Figure 4 shows the experimental expansion angles vs. stagnation pressure. The stagnation or pitot pressure is the pressure at which the fluid will come to rest, i.e., sum of the dynamic pressure and static pressure. The spread angle in the expansion region increased with pressure, whereas the expansion angle in the developed region slightly changed around an average value of about $7^{\circ}$. 


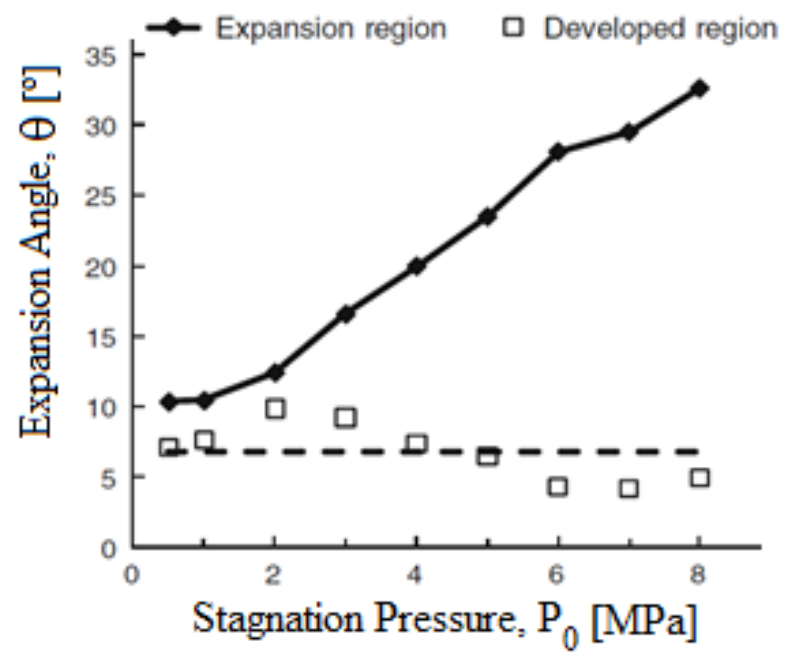

Figure 4. Expansion angle vs. stagnation pressure (Someya, 2011)

\subsubsection{FLOW CONDITIONS}

The Bubnov model (Bubnov, 1998) has been chosen to characterize the flow conditions (pressure loss due to sudden expansion considered). According to this model, the value of the pressure at the transition point to choked flow, the so called critical pressure, may be written as:

$$
P_{\text {crit }}=P_{0}\left(\frac{2}{2+C_{\alpha}\left(1-C_{\beta}\right)(\gamma-1)}\right)^{\frac{\gamma}{\gamma-1}}
$$

where $\mathrm{C}_{\alpha}$ and $\mathrm{C}_{\beta}$ are the correction factors of the kinetic energy to account for the pulsating motion of a jet; and $\gamma$ is the isentropic expansion coefficient. The following empirical relation was obtained for a sudden flow expansion:

$$
C_{\alpha}\left(1-C_{\beta}\right)=2.6135-1.4891 \frac{w_{0}}{w_{1}}
$$

where $w_{0}$ and $w_{1}$ denote the cross-sectional areas of the narrow and expanded portions of the flow.

Depending on the flow conditions, different expressions are recommended to estimate gas flow velocity:

1- For critical condition (sonic velocity)

$P_{1}<P_{\text {crit }}$

$$
u_{\text {crit }}=c_{0} \sqrt{\frac{2}{2+C_{\alpha}\left(1-C_{\beta}\right)(\gamma-1)}}
$$

where $c_{0}=\sqrt{\gamma R T_{0}}$

2- For sub-critical condition (subsonic velocity)

$P_{1}>P_{\text {crit }}$ 


$$
\begin{aligned}
u & =\sqrt{\frac{2 \gamma}{C_{\alpha}\left(1-C_{\beta}\right)(\gamma-1)}\left[\frac{P_{0}}{\rho_{0}}-\frac{P_{1}}{\rho_{1}}\right]}= \\
& =c_{0} \sqrt{\frac{2}{C_{\alpha}\left(1-C_{\beta}\right)(\gamma-1)}\left(1-\left(\frac{P_{1}}{P_{0}}\right)^{\frac{\gamma-1}{\gamma}}\right)}
\end{aligned}
$$

\subsubsection{JET PENETRATION}

Only a few studies have been made related to a high velocity jets discharging into a liquid pool. Hoefele and Brimacombe (Hoefele, 1979) gave the following equation to calculate the penetration length (distance from the nozzle exit to the point at which the gas jet extinguishes and the rising plume begins, in practice, the distance from the nozzle exit to the intersection of the bottom part of the jet with the extension of the imaginary center line of the jet) for horizontal gas jets for an air/water system:

$$
\frac{L_{j e t}}{D_{0}}=10.7 F r^{0.46}\left(\frac{\rho_{g}}{\rho_{l}}\right)^{0.35}
$$

where the Froude number is defined by:

$$
F r_{g}=\frac{\rho_{g} u_{0}^{2}}{\left(\rho_{l}-\rho_{g}\right) g D_{0}}
$$

where $u_{0}$ and $D_{0}$ are the initial gas jet velocity and orifice diameter respectively.

\subsection{The End of the Entrainment Zone}

At the gas-liquid interface an intense mass, momentum and energy transfer can happen. Under certain conditions a fraction of the liquid film contacting the gas can enter the gas core in the form of droplets (i.e., entrainment) and at the same time droplets in the gas core can abandon it to deposit on the liquid phase. The point at which this mass exchange starts is called "onset of entrainment". A number of criteria have been proposed (Crowe, 2006; Ishii, 1975; Owen, 1987) under annular flow configuration, but the Ishii and Grolmes one is strongly credited.

For liquid Reynolds numbers higher than the onset of entrainment value, $R e_{1}>R_{\text {ffOE }}\left(R e_{f f O E} \approx 160\right)$ the inception criterion proposed by Ishii and Grolmes is

$$
\begin{gathered}
u_{g} \geq 11.78 N_{\mu}^{0.8} \operatorname{Re}_{/}^{-1 / 3} \frac{\sigma}{\mu_{l}} \sqrt{\frac{\rho_{l}}{\rho_{g}}} \text { for } N_{\mu} \leq \frac{1}{15} ; \operatorname{Re} e_{l} \leq 1635 \\
u_{g} \geq 1.35 \operatorname{Re}_{/}^{-1 / 3} \frac{\sigma}{\mu_{l}} \sqrt{\frac{\rho_{l}}{\rho_{g}}} \quad \text { for } N_{\mu}>\frac{1}{15} ; \operatorname{Re} e_{/} \leq 1635
\end{gathered}
$$

For the rough turbulent regime $\left(\mathrm{Re}_{\mathrm{P}}>1635\right)$ the inception criterion is: 


$$
\begin{aligned}
& u_{g}>\frac{\sigma}{\mu_{l}} \sqrt{\frac{\rho_{l}}{\rho_{g}}} \times N_{\mu}^{0.8} \text { for } N_{\mu} \leq \frac{1}{15} ; \operatorname{Re}_{/}>1635 \\
& u_{g}>\frac{\sigma}{\mu_{l}} \sqrt{\frac{\rho_{l}}{\rho_{g}}} \times 0.1146 \text { for } N_{\mu}>\frac{1}{15} ; \operatorname{Re}_{/}>1635
\end{aligned}
$$

where $u_{g}$ is the gas superficial velocity (this gas velocity limit value is usually called "entrainment inception velocity", $\mathrm{u}_{\mathrm{inp}}$ ) and $\mathrm{N}_{\mu}$ is the viscosity number, originally used by Hinze (Hinze, 1955), which compares the viscous force induced by an internal flow to the surface tension force. It is defined as

$$
N_{\mu}=\frac{\mu_{l}}{\left(\rho_{/} \sigma \sqrt{\frac{\sigma}{g \Delta \rho}}\right)^{1 / 2}}
$$

\subsection{Characterization of the Liquid Phase}

Regarding the liquid phase, the key parameters are the liquid velocity and the liquid film thickness which is disturbed by the submerged gaseous jet. It is also important to estimate the interfacial forces present in the gas-liquid interface. In the next paragraphs these magnitudes will be estimated.

\subsubsection{INTERFACIAL SHEAR STRESS AND LIQUID VELOCITY}

The interfacial shear stress $\left(\tau_{\text {friction }}\right)$ determines the momentum exchange between gas and liquid:

$$
\tau_{\text {friction }}=\frac{1}{2} f_{g i} \rho_{g}\left(u_{g}-u_{l}\right)^{2}
$$

The gas-liquid interface in a parallel base flow is controlled by the instabilities of Kelvin-Helmholtz generated in inviscid theory by the velocity difference (Yecko, 2002):

$$
u_{l}=u_{g} \sqrt{\frac{\mu_{g}}{\mu_{l}} \frac{\rho_{l}}{\rho_{g}}}
$$

The interfacial friction factor is approximated through Ohnuki's correlations (Spore, 2000).

$$
f_{g i}=1.84 f_{w g}
$$

where

$$
f_{w g}=\left\{\begin{array}{l}
\frac{16}{\operatorname{Re}_{g}} ; \operatorname{Re}_{g}<2100 \\
\frac{0.079}{\operatorname{Re}_{g}^{0.25}} ; 2100<\operatorname{Re}_{g}<10^{5} \\
0.0008+\frac{0.05525}{\operatorname{Re}_{g}^{0.237}} ; \operatorname{Re}_{g} \geq 10^{5}
\end{array}\right.
$$




\subsubsection{PERTURBED LIQUID FILM THICKNESS}

In order to determine the perturbed liquid film thickness the superficial wave amplitude will be estimated first. To do so the following expression have been used (Mantilla, 2008),

$$
\Delta h_{w}=2 C_{w} \frac{\mu_{I}}{\rho_{l}} \sqrt{\frac{\rho_{I}}{\rho_{g}}} \frac{1}{\sqrt{f_{g i} f_{l i}}} \frac{1}{u_{g}-u_{l}}
$$

being $\mathrm{C}_{\mathrm{w}}$ a factor that accounts for the effect of the surface tension on the circulation/dissipation flow in the wave, which is defined as follows

$$
\begin{array}{lll}
C_{W}=0.028 N_{\mu}^{-4 / 5} & \text { for } & N_{\mu} \leq 1 / 15 \\
C_{W}=0.25 & \text { for } & N_{\mu}>1 / 15
\end{array}
$$

where $N_{\mu}$ is the viscosity number defined in Eqn. (9), and $f_{g i}$ is the gas interfacial friction factor, defined in Eqns. (12) and (13) and $f_{i j}$ is the liquid interfacial friction factor that is calculated utilizing the correlation developed by Hughmark (Berna, 2014),

$$
\sqrt{f_{l i}}=K \mathrm{Re}_{l}^{m}
$$

where $\mathrm{K}$ and $\mathrm{m}$ are given by

$$
\begin{aligned}
& K=3.73, m=-0.47 \text { for } 2<\operatorname{Re}_{1}<100 \\
& K=1.962, m=-1 / 3 \text { for } 100<\operatorname{Re}_{1}<1000 \\
& K=0.735, m=-0.19 \text { for } 1000<\operatorname{Re}_{\mid}
\end{aligned}
$$

Moreover the critical wavelength, $\lambda_{c, K-H}$, for a Kelvin-Helmholtz instability can be defined as

$$
\lambda_{c, K-H}=2 \pi \sqrt{\frac{\sigma_{l}}{g\left(\rho_{l}-\rho_{g}\right)}}
$$

Finally, assuming that the perturbed liquid film thickness can be defined as the square root of the product of the last two variables, Eqns. (14) and (17), we can obtain the liquid film thickness as:

$$
\delta_{I}=\sqrt{\lambda_{c, K-H} \cdot \Delta h_{w, K-H}}
$$

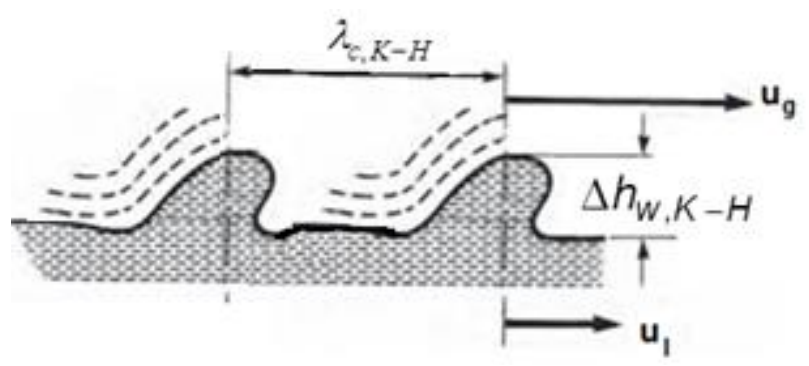

Figure 5. Schematic wave representation of the Kelvin-Helmholtz instability

\subsection{Droplet Sizes}


The entrained droplets are surrounded by a gaseous phase which is moving at a high relative velocity, consequently the aerodynamic forces might cause the deformation and fragmentation of these droplets. Then the droplets with a diameter larger than the maximum stable size oscillate up to breaking up. Consequently, the entrained droplets distribute in a truncated size distribution function with a maximum value, usually the upper-limit log-normal (Crowe, 2006). The stability diameter can be estimated through non-dimensional Weber number (ratio of gas kinetic energy and liquid cohesive energy),

$$
\phi_{d, \text { max }}=\frac{\sigma W e_{c r i t}}{\rho_{g} u_{g}^{2}}
$$

which has been correlated through the following equation developed by Kolev (Kolev, 2007):

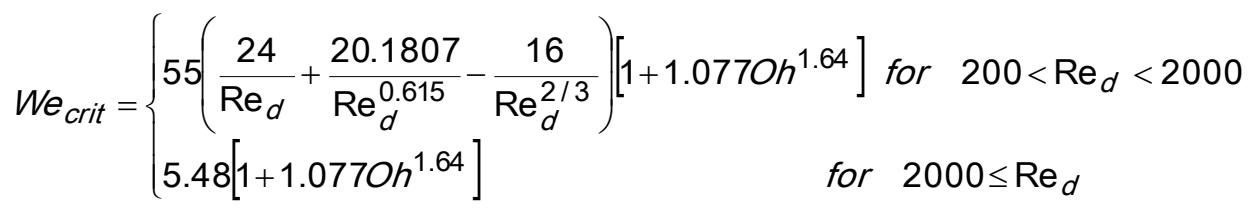

being $\mathrm{Re}_{\mathrm{d}}$ the droplet Reynolds number defined as

$$
\operatorname{Re}_{d}=\frac{\rho_{d}\left(u_{g}-u_{d}\right) \phi_{d}}{\mu_{g}}
$$

and the Ohnesorge dimensionless number, which is a relation between viscosity and the product of inertia and surface tension forces, defined as

$$
O h=\frac{\mu_{l}}{\sqrt{\rho_{l} \sigma D}}
$$

Another family of correlations is directly based on fluid dynamic characterization of the scenario. A recent expression (Berna, 2015b) has been derived:

$$
\frac{\phi_{v m}}{D}=2.634 \cdot W e_{g}^{-0.23} \operatorname{Re}_{g}^{-0.54} \mathrm{Re}_{j}^{0.13}
$$

Given the discrepancies between these two kinds of equations, in this work the average of them, Eqns. (20) and (23), has been adopted. It has been combined the "aggressiveness" of the first kind, sudden exposure to a high speed gaseous stream, with the "smoothness" of the second one, expression for fully developed annular flow.

\subsection{Droplet Velocity Profile}

There are very few data of droplet velocity within the gas core. Recently, Someya et al. (Someya, 2011) observed that the entrained droplets travel between $1 / 30-1 / 60$ of the submerged gaseous jet velocity. Whereas other approximations found in the open literature, even though were developed for fully developed annular flows, assume that droplet velocities are much higher, being between $0.5-0.8$ of gas velocity (Fore, 1995; Azzopardi, 1997). 
In this work the expression chosen for droplet velocity considers the velocity at which the entrained droplets leave the interface (wave celerity, c), added to a percentage of the gas velocity. The expression is as follows

$$
u_{d}=c+0.15 \cdot u_{g}
$$

being $c$ the wave celerity (velocity at which the gas-liquid interface waves are travelling), defined as Kumar suggested (Mantilla, 2008)

$$
c=\frac{\psi \cdot J_{g}+J_{l}}{1+\psi}
$$

and the parameter $\psi$ is

$$
\psi=5.5 \sqrt{\frac{\rho_{g}}{\rho_{/}}\left(\frac{\mathrm{Re}_{/}}{\mathrm{Re}_{g}}\right)^{0.25}}
$$

\subsection{Droplet Concentration into the Gas Jet}

\subsubsection{ENTRAINMENT MASS FLUX}

Recently, based on annular flow data, the authors derived an expression (Berna, 2015b) that depends on fluid properties of the scenario:

$$
\frac{E}{1-E}=5.51 \times 10^{-7} \cdot W e_{g}^{2.68} \operatorname{Re}_{g}^{-2.62} \operatorname{Re}_{/}^{0.34}\left(\frac{\rho_{g}}{\rho_{l}}\right)^{-0.37}\left(\frac{\mu_{g}}{\mu_{l}}\right)^{-3.71} C_{W}^{4.24}
$$

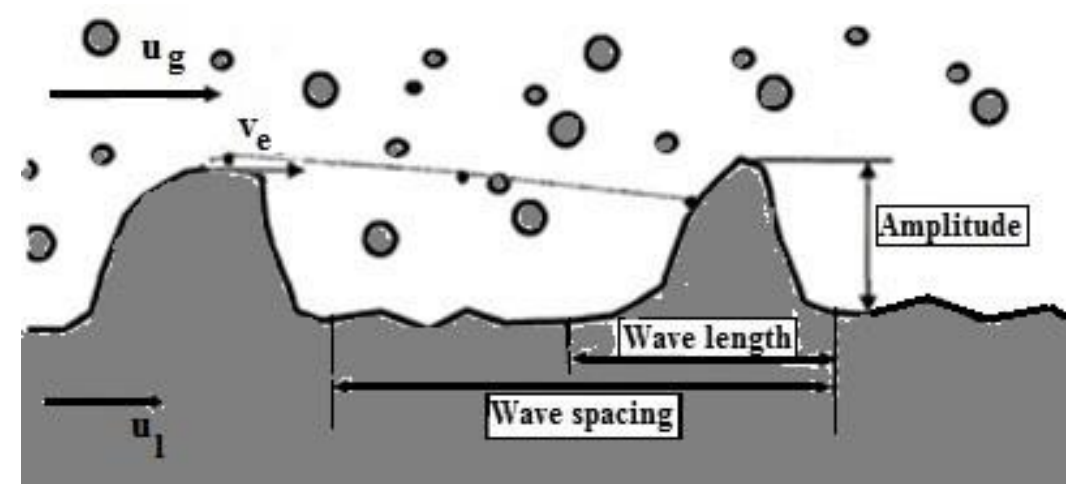

Figure 6.Schematic view of droplet entrainment-deposition process

In the case under study, this expression has been modified since the above equation was obtained for fully developed flow conditions, which is not the case of a submerged jet (continuous expansion as it moves away from the nozzle, unsteadiness and pulsating behavior). Then, this expression has been corrected to account for the flow development based on the work by Kataoka et al. (Kataoka, 2000), adopting a similar expression to the one he proposed but with a shorter and aggressive transition to developed flow (i.e., the constant has been increased from $1.8710^{-5}$ to $2.75 \cdot 10^{-4}$ ):

$$
E(z)=\left[1-\exp \left(-2.75 \cdot 10^{-4} \frac{(z / D)^{2} \mathrm{Re}_{/}}{W e_{g}^{0.5}}\right)\right] E
$$

being $z$ the axial distance to the nozzle and $D$ the jet diameter. 


\subsubsection{DROPLET DEPOSITION}

The amount of droplets that remain into the gaseous jet decreases exponentially as it evolves downstream, this is caused by the deposition processes, i.e. opposite situation to the entrainment process. The used expression is

$$
N_{d}(z)=N_{d o} e^{\frac{-\Delta z}{I_{c}}}
$$

where $\Delta z$ is the distance in the axial jet direction from the cell in which the droplet has been dragged from the liquid interface, $N_{d o}$ is the initial droplet population, $\mathrm{N}_{\mathrm{d}}(\mathrm{z})$ is the droplet concentration at a given distance from the inlet, and $I_{c}$ is the characteristic length that accounts for the droplet motion towards the liquid interface.

\section{AEROSOL CAPTURE MECHANISMS}

Single droplet may collect particles via one or more of the several collection mechanisms, such as impaction, interception, Brownian diffusion, electrostatic attraction, diffusiophoresis, thermophoresis, etc. Although all these capturing mechanisms might play some role in the scenario under consideration, at the present stage of the work the attention has been focused on those related to droplet-particle mechanical interactions (Figure 7), that is: inertial impaction, interception and Brownian diffusion. Hence, considering that the aerosol capture mechanisms are not entirely independent, finally the expression employed to take into account the combined effects of the three mechanisms is:

$$
\eta=1-\left(1-\eta_{\text {impact }}\right) \cdot\left(1-\eta_{\text {int ercep }}\right) \cdot\left(1-\eta_{\text {diff }}\right)
$$

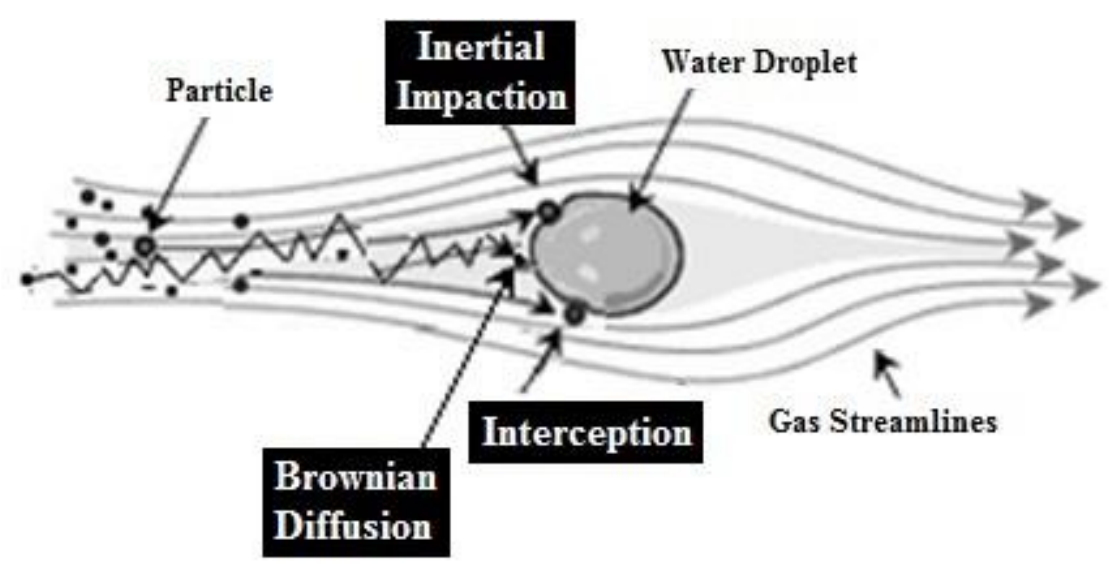

Figure 7. Sketch of droplet-particle mechanical interaction

The correlations presented below for aerosol scrubbing by the entrained droplets have been taken from domain of wet scrubbers, as droplet hydro conditions are probably closer to submerged jets than annular flow ones.

\subsection{Inertial Impaction}

Heavy particles might be removed from the carrier flow due to sudden changes of direction caused by the presence of obstacles. Particle inertia would 
make them move to away the gas streamlines and eventually collide with the obstacle.

Among the different available expressions in the literature, the one proposed by Slinn (Flagan, 1988) is employed here

$$
\eta_{\text {impact }}=\left(\frac{S t k-S^{*}}{S t k+\frac{2}{3}-S^{*}}\right)^{3 / 2}\left(\frac{\rho_{d}}{\rho_{p}}\right)^{1 / 2} \quad \text { for } S t k>S^{*}
$$

where

$$
S^{*}=\frac{1.2+\frac{1}{12} \operatorname{Ln}\left(1+\frac{\mathrm{Re}_{d}}{2}\right)}{1+\operatorname{Ln}\left(1+\frac{\operatorname{Re}_{d}}{2}\right)}
$$

where Stk is the particle Stokes number (Crowe, 2006),

$$
S t k=\frac{C_{c} \rho_{p} \phi_{p}^{2}\left(u_{g}-u_{d}\right)}{9 \mu \phi_{d}}
$$

being $\mathrm{C}_{\mathrm{c}}$ the Cunningham slip-correction factor

$$
C_{c}=1+2.493 \frac{\lambda}{\phi_{p}}+0.84 \frac{\lambda}{\phi_{p}} \exp \left(-0.435 \frac{\phi_{p}}{\lambda}\right)
$$

in which $\lambda$ is the mean free path length of the water molecules in air. For air at $1.01 \cdot 10^{5} \mathrm{~Pa}$ and $293 \mathrm{~K}$ the mean free path is $\lambda_{\text {ref }}=0.0664 \mu \mathrm{m}$, while for air at other conditions the following formula, proposed by Willeke (Crowe, 2006), can be used

$$
\lambda=\lambda_{\text {ref }}\left(\frac{1.01 \cdot 10^{5}}{P}\right)\left(\frac{T}{293}\right)\left(\frac{1+\frac{110}{293}}{1+\frac{110}{T}}\right)
$$

where the pressure, $\mathrm{P}$, is in $\mathrm{Pa}$ and the temperature, $\mathrm{T}$, in $\mathrm{K}$.

\subsection{Interception}

Interception takes place when the aerosol particle radius is larger than the distance between the streamline followed by the aerosol particle and the surface of the obstacle (in the present case, the water droplets). Lots of expressions are available in the open literature and many of them have been tested in the present work, for instance the Zhao and Zheng's correlation (Zhao, 2008), Slinn's correlation (Flagan, 1988), etc. Finally the selected correlation was the one proposed by Jung and Lee's (Jung, 1998), which is:

$$
\eta_{\text {int ercep }}=\frac{1-a}{J+b K}\left[\frac{\phi_{p} / \phi_{d}}{1+\phi_{p} / \phi_{d}}+\frac{1}{2}\left(\frac{\phi_{p} / \phi_{d}}{1+\phi_{p} / \phi_{d}}\right)^{2}(3 b+4)\right]
$$


where $a=\left(r_{d} / r_{g}\right)^{3}$ being $r_{d}$ is the sphere radius and $r_{g}$ is the boundary radius (jet radius); $b=\frac{\mu_{l}}{\mu_{g}} ; J=1-\frac{6}{5} a^{1 / 3}+\frac{1}{5} a^{2}$ and $K=1-\frac{9}{5} a^{1 / 3}+a+\frac{1}{5} a^{2}$.

\subsection{Brownian Diffusion}

Brownian motion is the random movement of particles suspended in a fluid. Several expressions have been tested too, and finally the correlation selected to consider the collection efficiency by this diffusion motion is the one given by Jung and Lee (Jung, 1998):

$$
\eta_{\text {diff }}=0.7\left[\frac{4}{\sqrt{3}}\left(\frac{1-a}{J+b K}\right)^{1 / 2} P e^{-1 / 2}+2\left(\frac{\sqrt{3} \pi}{4 P e}\right)^{2 / 3}\left[\frac{(1-a)(3 b+4)}{J+b K}\right]^{1 / 3}\right]
$$

being the Peclet number defined as

$$
P e=\frac{\phi_{d} u_{d}}{D_{\text {diff }}}
$$

and the diffusion coefficient

$$
D_{\text {diff }}=\frac{K_{b} T C_{c}}{3 \pi \mu_{g} \phi_{p}}
$$

where $\mathrm{K}_{\mathrm{b}}$ is the Boltzmann constant, $\mathrm{C}_{c}$ was defined in Eqn. (34) and, the coefficients $\mathrm{a}, \mathrm{b}, \mathrm{J}$ and $\mathrm{K}$ are defined as in the previous impaction mechanism. This expression can be used when the viscosity ratio of both fluids ranges between 1 and 100, which is the case of water droplets traveling into the gaseous jet.

\section{THE ORIGINAL SPARC90 CODE}

Several specific codes for pool scrubbing were developed from the middle 80s until the early 90s, such as SPARC90 (Owczarski, 1991), BUSCA (Ramsdale, 1991) and SUPRA (Wassel, 1985). All of them modeled gas injection under the "globule regime", so that gas-liquid interactions under jet injection regime are missing.

The SPARC90 (Suppression Pool Aerosol Removal Code) was developed by the Pacific Northwest Laboratory. In its input file it should be included, among others, the geometric and thermal-hydraulic conditions of the pool and the thermal-hydraulic conditions and composition of the injected gas. From these data SPARC90 calculates the DF as a function of aerosol particle sizes and his total value, among other parameters related to bubble and aerosol information.

The SPARC90 code incorporates five aerosol scrubbing models and two thermal-hydraulic models (Owczarski, 1985). The aerosol scrubbing process is described by: convective flows from the condensation of steam, growth of soluble particles by water vapor sorption, gravitational settling (sedimentation), inertial deposition due to circulation of the bubble surface and diffusional deposition. The thermal-hydraulic model consists of two parts, in the first one, 
the model for the equilibrium pool temperature is described. This is the steadystate temperature of the pool in thermal and vapor equilibrium with the gas leaving the pool. The second part is the model for steam evaporation into the bubble as it rises. This incoming steam is the result of the steam maintaining vapor equilibrium as the bubble rises. This steam influx retards all particle deposition mechanisms, and it is especially important in pools near the boiling point.

All these models have been designed and applied to the determination of aerosol pool trapping during vent discharge processes in the suppression pools of BWR reactors under severe accident conditions. Such discharge occurs at low gas velocities. However, there are accident sequences, like SGTR core meltdown sequences, at which particle laden gases reach the aqueous ponds at very high velocities and new particle removal mechanisms become effective right at the nozzle or break inlet.

\section{NEW MODEL IMPLEMENTATION}

The SPARC90-Jet model, presented in the previous sections, has been implemented as a subroutine of the original SPARC90 Fortran code (Owczarski, 1991). This work outlines the fundamentals, major hypotheses and changes introduced into the code in order to estimate particle removal during gas injection in pools under jet regime. To do so, a simplified and reliable approach to submerged jet hydrodynamics has been developed to describe both the gasliquid and the drop-particles interactions. This paper summarizes this update process of the SPARC90 code to capture the phenomena which take place under high velocity injection conditions (SPARC90-Jet), it is based on the stateof-the-art equations for jet hydrodynamics and aerosol removal (remind that the its old version was only developed for low velocity injection regimes).

Regarding the programming of the SPARC90-Jet, when the jet option is activated the new subroutine of the SPARC90-Jet is called, this subroutine continues to be active until gas jet velocity is below the onset of the entrainment zone, moment in which is considered that the gaseous jet extinguishes. From this point, the code performs the same calculations as the original code, that is, the rising plume decontamination factor, although starting from different conditions. But with a significant difference, in our case, the globule formation region has been removed, consequently only the rising plume in which the bubbles evolve with a single diameter to represent the swarm exists, for noncondensable gases this value corresponds to the volume mean diameter, i.e. $0.72 \mathrm{~cm}$.

The structure of the SPARC90-Jet is sequentially programmed in two main parts: hydrodynamics and aerosol scrubbing by droplets. In order to implement the expressions developed in sections 2 and 3 within SPARC90, the jet entrainment zone has been split into a large number of nodes (Figure 8). 


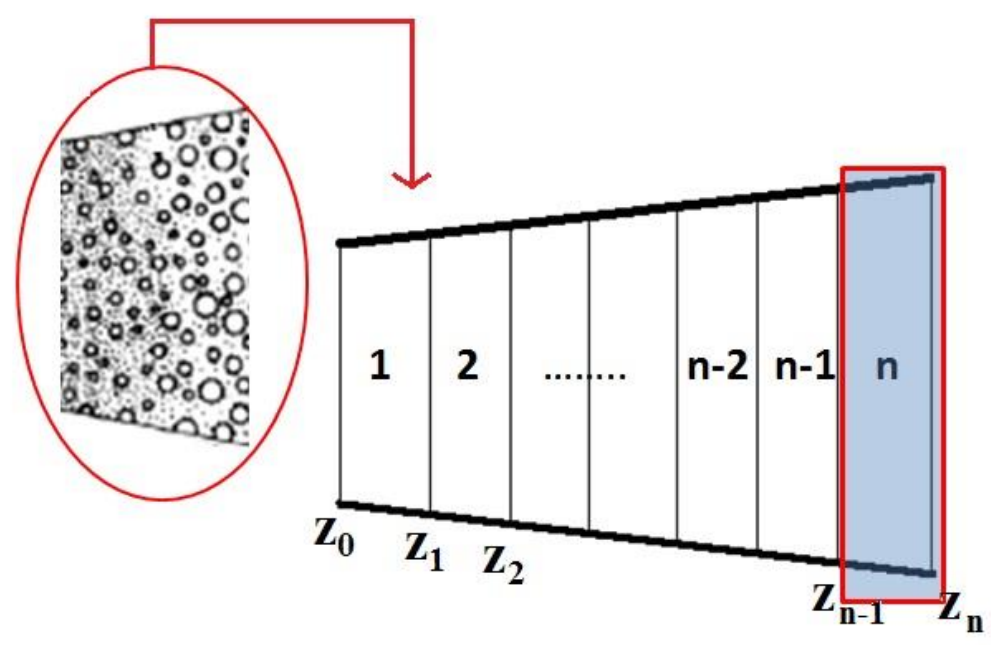

Figure 8. Jet nodalization

\subsection{The Conservation Equations}

The determination of the axial velocity profile is a key issue to characterize the gaseous jet. To achieve this modeling, the Epstein model (Epstein, 1990) has been used as a starting point. This model considers three conservation equations: gas mass conservation, liquid mass conservation and momentum conservation.

Attending to the entrained droplets, say that the total amount of droplets dragged by the gas stream in the cell $n, \dot{m}_{1}(n)$, is given by:

$$
\dot{m}(n)=(2 \pi \bar{R} z) \Delta z)) \rho_{l} v_{d}(n)
$$

where $v_{e}(n)$ is the entrainment velocity in the cell $n$ (this velocity is an effective drag velocity, that is to say, the extraction velocity of droplets minus the deposition velocity of droplets), this velocity is obtained from Ricou and Spalding theory (Ricou, 1961)

$$
\left.\left.v_{d} n\right)=e_{0} u_{g} n\right) \sqrt{\frac{(\alpha n)}{\rho_{l}}}
$$

where the entrainment coefficient, $e_{0}$, varies from 0.058 to 0.116 , and the density in cell $n, \rho(n)$, is given by

$$
(k n)=(n) \rho_{g}+[1-\not(n)] \rho_{l}
$$

then, the liquid mass conservation equation can be written as:

$$
\left.\left.\frac{d}{d z}\left[\rho_{/}(1-\alpha(z)) u_{/}(z) \pi R^{2}(z)\right]=2 \pi \bar{R} z\right) \rho_{/} v_{d} z\right)
$$

being $\bar{R}(z)$ the average jet radius of each cell.

Integration over the limits of node $n\left(z_{n-1}, z_{n}\right)$ yields to:

$$
\left.\left.\rho_{l}(1-\alpha(n)) u_{l}(n) R^{2}(n)-\rho_{l}(1-\alpha(n-1)) u_{l}(n-1) R^{2}(n-1)=2 \bar{R} n\right) \rho_{l} v_{\S} z\right) \Delta z
$$


from where, taking into account that the liquid phase velocity , $\mathrm{u}_{\mathrm{l}}$, is the droplet velocity, $u_{d}$. Then, solving for the liquid fraction one has

$$
(1-\alpha(n))=(1-\alpha(n-1)) \frac{u_{d}(n-1) R^{2}(n-1)}{u_{d}(n) R^{2}(n)}+\frac{\left.\left.2 v_{d} n\right) \bar{R} n\right) \Delta z}{u_{d}(n) R^{2}(n)}
$$

The continuity condition imposes that the product of the entrained droplet velocities by the cell radius squared in adjacent cells are very similar, therefore Eqn. (45) can be written as:

$$
(1-\alpha(n))=(1-\alpha(n-1))+\frac{\left.\left.2 v_{d} n\right) \bar{R} n\right) \Delta z}{u_{d}(n) R^{2}(n)}
$$

Applying this recurrence relation along the submerged jet ${ }^{1}$,

$$
(1-\alpha(n))=\sum_{k=1}^{n} \frac{\left.\left.2 v_{d} k\right) \bar{R} k\right) \Delta z}{u_{d}(k) R^{2}(k)}
$$

Solving from the previous equation the void fraction the following expression is reached

$$
\alpha(n)=1-\sum_{k=1}^{n} \frac{\left.\left.2 v_{e, j} k\right) \bar{R} k\right) \Delta z}{u_{d, j}(k) R^{2}(k)}
$$
by

Moreover, we have the jet momentum conservation equation, which is given

$$
\frac{d}{d z}\left[(1-\alpha(z)) \rho_{/} u_{J}^{2}(z) \pi R^{2}(z)\right]+\frac{d}{d z}\left[\alpha(z) \rho_{g} u_{g}^{2}(z) \pi R^{2}(z)\right]+\tau_{\text {friction }} 2 \pi R(z)=0
$$

being $\alpha(z)$ the void fraction, $u_{l}(z)$ the liquid velocity, $u_{g}(z)$ the gas velocity, $R(z)$ the jet radius, all of them in the axial coordinate $z$, and $\tau_{\text {friction }}$ is the friction shear stress force between the gas jet and the surrounding water.

The first term in Eqn. (49) is due to the momentum flux of entrained droplets, the second is due to the gas momentum flux and the third term is produced by the friction losses.

Note that several assumptions have been made: jet conical shape; no phase change and constant velocity along the radial coordinate; a gas jet expansion zone is considered, in which pressure equals the pool pressure (Bubnov, 1998).

Integration of the Eqn. (49) over cell $n$ gives:

$$
\begin{aligned}
& (1-\alpha(n)) \rho_{l} u_{l}^{2}(n) R^{2}(n)+\alpha(n) \rho_{g} u_{g}^{2}(n) R^{2}(n)+\tau_{\text {friction }} 2 \bar{R}(n) \Delta z= \\
& (1-\alpha(n-1)) \rho_{l} u_{l}^{2}(n-1) R^{2}(n)+\alpha(n-1) \rho_{g} u_{g}^{2}(n-1) R^{2}(n-1)
\end{aligned}
$$

\footnotetext{
${ }^{1}$ In the general case, in which a droplet size distribution function would be considered in each cell, the Eqn. (48) will be written as:

$$
\alpha(n)=1-\sum_{j=1}^{N_{\text {sizes }}} \sum_{k=1}^{n} \frac{\left.\left.2 v_{e, j} k\right) \bar{R} k\right) \Delta z}{u_{d, j}(k) R^{2}(k)}
$$
}


Moreover, at the inlet region, the initial gaseous jet momentum is given by:

$$
M_{0}=\rho_{0} u_{0}^{2} \pi R_{0}^{2}
$$

being the gas density along the submerged gaseous jet equal to the inlet gas density, $\rho_{g}=\rho_{0}$ (actually not at the nozzle exit, but just after the initial jet expansion).

Therefore, it can be written for any cell $n$ :

$$
(1-\alpha(n)) \rho_{l} u_{J}^{2}(n) R^{2}(n)+\alpha(n) \rho_{g} u_{g}^{2}(n) R^{2}(n)+\sum_{k=0}^{n} \tau_{\text {friction }, k} 2 \bar{R}(k) \Delta z=\rho_{0} u_{0}^{2} R_{0}^{2}
$$

By substituting the expression of the void fraction, Eqn. (47), in the above equation and dividing by $R^{2}(n)$ one has:

$$
\left.\alpha(n) \rho_{g} u_{g}^{2}(n)+\sum_{k=1}^{n} \frac{\left.\left.2 v_{d} k\right) \bar{R} k\right) \Delta z}{u_{d}(k) R^{2}(k)} \rho_{l} u_{d}^{2} n\right)+\sum_{k=1}^{n} \tau_{\text {friction }, k} 2 \frac{\bar{R}(k)}{\left.R^{2} n\right)} \Delta z=\rho_{0} u_{0}^{2} \frac{R_{0}^{2}}{\left.R^{2} n\right)}
$$

Using the gas mass conservation equation:

$$
\left.\left.\frac{d}{d z}\left(\rho_{g} \alpha z\right) u_{g}(z) \pi R^{2} z\right)\right)=0
$$

Integration over the node $\mathrm{n}$ with limits $\mathrm{z}_{\mathrm{n}-1}$ and $\mathrm{z}_{\mathrm{n}}$ yields to:

$$
\left.\alpha(n) u_{g} n\right) R^{2}(n)-\alpha(n-1) u_{g}(n-1) R^{2}(n-1)=0
$$

then, from the boundary condition at the entrance, $\alpha(0)=1$, it can be written:

$$
\left.\alpha(n) u_{g}(n) R^{2}(n)=\alpha(0) u_{g} 0\right) R^{2}(0)=u_{0} R_{0}^{2}
$$

which can be written as:

$$
\alpha(n) u_{g}(n)=u_{0} \frac{R_{0}^{2}}{R^{2}(n)}
$$

Substituting this expression into Eqn. (53) and solving for the gas velocity in the node $\mathrm{n}$, finally we have:

$$
\left.u_{g}(n)=u_{0}-\frac{R^{2}(n)}{\rho_{0} u_{0} R_{0}^{2}} \sum_{k=1}^{n} \frac{\left.\left.2 v_{d} k\right) \bar{R} k\right) \Delta z}{u_{d}(k) R^{2}(k)} \rho_{l} u_{d}^{2} n\right)-\frac{1}{\rho_{0} u_{0} R_{0}^{2}} \sum_{k=1}^{n} \tau_{\text {friction }, k} 2 \bar{R}(k) \Delta z
$$

then, with the reorganization of the last expression one comes to

$$
\left.u_{g}(n)=u_{0}-2 \frac{\rho_{I}}{\rho_{0}} \frac{\Delta z}{u_{0}} \frac{R^{2}(n)}{R_{0}^{2}} \sum_{k=1}^{n} \frac{\left.\left.v_{d} k\right) \bar{R} k\right)}{u_{d}(k) R^{2}(k)} u_{d}^{2} n\right)-2 \frac{\Delta z}{\rho_{0} u_{0} R_{0}^{2}} \sum_{k=1}^{n} \tau_{\text {friction }, k} \bar{R}(k)
$$

\subsection{Calculation of the Decontamination Factor}

The Decontamination Factor (DF) is the ratio of the aerosol mass flow rate entering the system to the one that goes out of the system,

$$
D F=\frac{\dot{m}_{\text {in }}}{\dot{m}_{\text {out }}}=\frac{1}{1-\eta}
$$


being $\eta$ the particle collection efficiency $\left(\eta=\dot{m}_{\text {ret }} / \dot{m}_{\text {in }}\right)$.

\subsubsection{BUILDING THE OVERALL DECONTAMINATION FACTOR}

Owing to the decontamination process is composed of several stages, the particles DF of a given size is the product of the elementary DF's corresponding to each stage or cell:

$$
D F=\prod_{n} D F_{h}(k)
$$

being $\mathrm{k}$ the particle size index and $\mathrm{n}$ the stage number.

In the general case, the system inlet, the airborne fission products corresponds to a particle distribution whose size is due to the deposition, transportation and characteristics of the upstream primary circuit. For experimental systems particle distribution depends on the aerosol generator. The usual assumption is that there is no interaction between particles of different sizes (the transit time is too short to allow significant agglomeration) and all decontamination mechanisms are linear (no effect of aerosols on gas and liquid velocity fields). Consequently, it is not necessary to know the airborne concentration of each size class, just knowing the mass fraction.

Let $F_{0}(k)$ be the mass fraction at the inlet of the particles of a given size. Then the overall DF is given by:

$$
\left.\left.\frac{1}{D F}=\frac{\dot{m}_{\text {out }}}{\dot{m}_{\text {in }}}=\frac{1}{\dot{m}_{\text {in }}} \sum_{k} \dot{m}_{\text {ir }} k\right) \frac{\left.\dot{m}_{\text {out }} k\right)}{\left.\dot{m}_{\text {ir }} k\right)}=\sum_{k} F_{d} k\right) \cdot \frac{1}{D F k)}
$$

being,

$$
\left.F_{d} k\right)=\frac{\left.\dot{m}_{i k} k\right)}{\dot{m}_{i n}}
$$

The mass fraction at any other stage is given by:

$$
\left.F(k)=\frac{\dot{m}_{\text {out }}(k)}{\dot{m}_{\text {out }}}=\frac{\dot{m}_{\text {out }}(k)}{\dot{m}_{\text {ir }}(k)} \frac{\left.\dot{m}_{\text {ir }} k\right)}{\dot{m}_{\text {out }}}=\frac{1}{D F k)} \cdot D F \cdot F_{d} k\right)
$$

\subsubsection{INERTIAL CAPTURE BY YHE ENTRAINED DROPLETS OF THE SUBMERGED GAS JET}

In the Epstein model, the fundamental mechanism in the inertial capture by the entrained droplets is the velocity difference between the gas phase and the liquid droplets.

The airborne mass in the class size $\mathrm{k}$ collected by an individual droplet per second is:

$$
\left.\dot{m}_{j k} z\right)=-\frac{\pi \phi_{d, j}^{2}}{4}\left[u_{d}(z)-u_{d,}(z)\right] \cdot c_{d}(k, z) \cdot \eta_{j k}(z)
$$

where $\phi_{d, j}$ is entrained droplet diameter with discrete size class $j, c_{p}(k, z)$ is the mass concentration of particles in the size class $k$ at the axial location $z$ and $\eta_{\mathrm{jk}}$ 
is the collection efficiency of particles in the size class $\mathrm{k}$ by the droplets of class j.

Assuming now that there is no screening between the droplets, the mass flow rate of particles in the size class $k$ collected within an axial mesh $z, z+d z$ is:

$$
\left.d \dot{M}_{A}(z)=-\sum_{j=1}^{\infty} N_{d, \lambda}(z) \cdot \dot{m}_{j k} z\right) \cdot d V
$$

where $\mathrm{n}(\mathrm{z})$ is the droplet size distribution in the axial position $\mathrm{z}$ and $\mathrm{dV}$ is a gas jet differential volume, $\left.d V=\pi R^{2} z\right) d z$.

Then, the mass of airborne particles of size class $k$ collected by the water droplets per unit time and length is:

$$
\left.\left.\left.\frac{d \dot{M}_{A}(z)}{d z}=-\sum_{j=1}^{(n z) \pi \phi_{d, j}^{2}} \frac{u_{d}}{4} z\right)-u_{d,(}(z)\right] \cdot \eta_{j k} z\right) \cdot c_{d}(k, z) N_{d, j}(z) \pi R^{2}(z)
$$

The mass flow rate of airborne particles of size class $k$ which are dragged by the gas jet through the gas surface is:

$$
\dot{M}_{A}(z)=\pi R^{2}(z)(z) u_{g}(z) c_{p}(k, z)
$$

Dividing Eqns. (67) by (68):

$$
\left.\left.\frac{1}{\left.\dot{M}_{A} z\right)} \frac{\left.d \dot{M}_{A} z\right)}{d z}=-\sum_{j=1}^{(\infty) \pi \phi_{d, j}^{2}} \frac{\left.\left[u_{d}(z)-u_{d,(} z\right)\right]}{\left.4(z) u_{d} z\right)} \cdot \eta_{j k} z\right) N_{d,(} z\right)
$$

defining,

$$
\left.x k, z)=\sum_{j=1}^{\phi(z)} \frac{\pi \phi_{d, j}^{2}}{4} \frac{\left.\left[u_{d}(z)-u_{d,(} z\right)\right]}{(z z) u_{g}(z)} \cdot \eta_{j k} z\right) N_{d,(}(z)
$$

Then,

$$
\left.\frac{\left.d \dot{M} \dot{M}_{A} z\right)}{\left.\dot{M}_{A} z\right)}=-\chi k, z\right) d z
$$

Integrating,

$$
\left.\left.\left[\operatorname{Ln} \dot{M}_{A} z\right)\right]_{z_{i}}^{z_{i}+\Delta z}=-\int_{z_{i}}^{z_{i}+\Delta z} x k, z\right) d z
$$

Consequently,

$$
\left.\left.\dot{M}_{A} z_{i}+\Delta z\right)=\dot{M}_{A}\left(z_{i}\right) \exp \left(-\int_{z_{i}}^{z_{i}+\Delta z} t k, z\right) d z\right)
$$

Finally the DF in the stage $\mathrm{i}$ :

$$
\left.\frac{\dot{M}_{A}\left(z_{i}\right)}{\dot{M}_{A}\left(z_{i+1}\right)}=\exp \left(+\int_{z_{i}}^{z_{i}+\Delta z} \chi k, z\right) d z\right)=D F(k)
$$


Decontamination Factor, DF, of airborne particles of size class $k$ is eventually estimated as the product of individual contributions of each axial node (i):

$$
\begin{aligned}
D F k)= & \frac{\dot{M}_{A}\left(z_{1}\right)}{\dot{M}_{A}\left(z_{2}\right)} \frac{\dot{M}_{A}\left(z_{2}\right)}{\dot{M}_{A}\left(z_{3}\right)} \cdots \frac{\dot{M}_{A}\left(z_{n}\right)}{\dot{M}_{A}\left(z_{n-1}\right)}=\prod_{i=1}^{N} D F(k)= \\
& \left.\left.=\exp \left(\sum_{i=1}^{N} \int_{z_{i}}^{z_{i}+\Delta z} x k, z\right) d z\right) \approx \exp \sum_{i=1}^{N} \chi k, z_{i}\right) \Delta z_{i}
\end{aligned}
$$

being $\gamma(\mathrm{k}, \mathrm{z})$ defined in Eqn. (70).

\subsection{Main Assumptions of the SPARC90-Jet Code}

In addition to the approximations associated with the expressions developed in the current section, this improved version of the SPARC90 code has implemented several approximations, among which, the following can be emphasized:

- Constant conical expansion ratio of the submerged gaseous jet along the injection direction.

- Thermal exchanges have not being taken into account, neither sensible nor latent heat transfer; this approximation would be rough in case that water temperature is well below saturation.

- Thermophoresis and diffusiophoresis have been neglected, which might result in the DF underprediction (particularly, for submicron particles).

- Droplets agglomeration/de-agglomeration processes have not been taken into account. It is assumed that interaction among droplets cannot take place along the pool discharge process.

- A mean diameter of the entrained droplets in each cell has been used, that is, only one constant diameter for the entrained droplets has been considered in each cell. Next step will be to consider a particle size discrete distribution function, among which the most appropriated for the present conditions seems to be the Log-Normal Distribution.

- Correlations for jet hydrodynamics have been mainly chosen from expressions developed for annular flows (for instance, correlations of droplet sizes, entrained fraction, etc.), due to the lack of information about submerged gaseous jets.

- Correlations for aerosol capture have been mainly chosen from expressions developed for wet scrubbers due to the lack of information specifically developed for submerged gaseous jets.

Consequently, the new model developed so far and presented in this paper should be considered as preliminary, existing still pending improvements in several areas, which will be carried out in subsequent works, though an important step has been taken with the development of the SPAR90-Jet code. For the development of some of these improvements it is necessary to conduct extensive experimentation specifically on submerged jets. To thereby, on the 
one hand, use the experimental data to develop expressions specific to submerged jet, while on the other, to provide experimental data to validate the results predicted by the new code SPARC90-Jet. The first set of experiments should focus on two aspects, determination of jet hydrodynamics and aerosol capture processes. While the second group, should focus on the measurement of DF's. Presently some experimental activities are ongoing of submerged jets within the EU PASSAM project (Herranz, 2014). For both aspects, the present code should be viewed not as a final version, but subject to revisions and improvements, as well as it is also subject to more extensive validation against experimental databases. So as soon as new data become available, works of development and validation of a new version of SPARC90-Jet will be carried out.

\section{RESULTS OF SPARC90-JET AND CONFRONTATION WITH EXPERIMENTAL DATA}

\subsection{Experimental Pool Scrubbing Scenarios}

In order to assess the capabilities of the SPARC90-Jet, a literature survey on pool scrubbing experiments has been carried out, in order to build up a huge database on jet injection regime. However, just few of those experiments met the jet regime conditions (We $\geq 10^{5}$ ). In addition, since the current version of SPARC90-Jet does not consider the thermally driven mass transfer, the selected experiments should not contain a high steam molar fraction, so that steam condensation does not affect the pool decontamination capability substantially. This screening out reduces the experimental programs providing useful data to ACE, LACE, POSEIDON II and RCA.

ACE experiments were framed within an international project led by EPRI (Escudero, 1995). Similarly to previous tests, they analyzed the influence of gas flow rate, steam fraction, submergence and aerosol size (Table 1). The only experimental sets having Weber numbers over $10^{5}$ were the AA1 and AA3 experiments.

LACE España Project began in 1987 as a Spanish participation in the international research program LACE (Escudero, 1995). As in the previous experiments, the main objectives were the analysis of discharge events in pools. Only two experiments met the jet regime, RT-SC-0/02 and RT-SC-P/01 (Table 1).

POSEIDON II program carried out a total of 17 experiments (Dehbi, 2001). They analyzed pool scrubbing dependence on carrier gas steam fraction, flow rate, particle size and submergence (Table 1). The chosen tests were PA10, PA11, PA12 and PA13 (We $\approx 5.5 \cdot 10^{6}-8 \cdot 10^{6}$ ), because of their low or null steam fraction, 0,04 for the first two and zero for the last two.

RCA experiments (López-Jiménez, 1996) were carried out in PECA facility located at CIEMAT. They were focused on the jet injection regime (We $\approx$ $2.9 \cdot 10^{6}-3.6 \cdot 10^{6}$ ) in hot pools. Four different experiments were performed with particles of around $4 \mu \mathrm{m}$ of AMMD (Aerodynamic Mass Median Diameter) and submergences from $0.25 \mathrm{~m}$ to $2.5 \mathrm{~m}$ (Table 1 ). 
Table 1. Summary of the main tests variables

\begin{tabular}{|c|c|c|c|c|c|c|c|c|c|c|}
\hline \multicolumn{11}{|c|}{ ACE Experimental conditions } \\
\hline \multirow{2}{*}{ TESTS } & \multirow{2}{*}{$\frac{\text { Nozzle }}{D_{N}(\mathrm{~cm})}$} & \multicolumn{4}{|c|}{ Gas Data } & \multicolumn{2}{|c|}{ Aerosol Data } & \multicolumn{3}{|c|}{ Pool Data } \\
\hline & & $\mathbf{P}$ (bar) & $\mathbf{T}\left({ }^{\circ} \mathbf{C}\right)$ & $\dot{\mathrm{m}}(\mathbf{g} / \mathbf{s})$ & $\mathbf{X}_{\mathrm{s}}$ & $\phi_{\mathrm{p}}(\mu \mathrm{m})$ & $\dot{\mathbf{m}}(\mathbf{g} / \mathbf{s})$ & \multicolumn{3}{|l|}{$P($ bar $)$} \\
\hline AA1 & 0.95 & 1.21 & 138 & 2.20 & 0.012 & 2.37 & 7.75E-03 & 1.0 & 26 & 1.38 \\
\hline AA3 & 0.95 & 1.32 & 150 & 2.16 & 0.013 & 2.50 & $1.03 \mathrm{E}-02$ & 1.0 & 82 & 2.62 \\
\hline \multicolumn{11}{|c|}{ LACE Experimental conditions } \\
\hline \multirow{2}{*}{ TESTS } & Nozzle & \multicolumn{4}{|c|}{ Gas Data } & \multicolumn{2}{|c|}{ Aerosol Data } & \multicolumn{3}{|c|}{ Pool Data } \\
\hline & $D_{N}(\mathrm{~cm})$ & $P($ bar $)$ & $\mathrm{T}\left({ }^{\circ} \mathrm{C}\right)$ & $\dot{m}(g / s)$ & $\mathbf{X}_{\mathrm{s}}$ & $\phi_{\mathrm{p}}(\mu \mathrm{r}$ & $\dot{\mathbf{m}}(\mathbf{g} / \mathbf{s})$ & $P($ bar $)$ & $\mathbf{T}\left({ }^{\circ} \mathrm{C}\right)$ & $S(m)$ \\
\hline $\begin{array}{c}\text { RT-SC- } \\
01 / 02\end{array}$ & 1.00 & 3.39 & 150 & 5.53 & 0.10 & 1.7 & $1.82 \mathrm{E}-0$ & 3.0 & 110 & 2.50 \\
\hline $\begin{array}{c}\text { RT-SC- } \\
\text { P/01 } \\
\end{array}$ & 1.00 & 3.39 & 150 & 5.36 & 0.11 & 5.6 & $1.82 \mathrm{E}-0$ & 3.0 & 110 & 2.50 \\
\hline \multicolumn{11}{|c|}{ POSEIDON II Experimental conditions } \\
\hline \multirow{2}{*}{ TESTS } & Nozzle & \multicolumn{3}{|c|}{ Gas Data } & \multicolumn{3}{|c|}{ Aerosol Data } & \multicolumn{3}{|c|}{ Pool Data } \\
\hline & $D_{N}(\mathbf{c m})$ & $\mathrm{T}(\stackrel{\circ}{ } \mathrm{C})$ & $\dot{\mathrm{m}}(\mathrm{g} / \mathrm{s}$ & $\mathbf{X}_{\mathrm{s}}$ & & $(\mu \mathrm{m})$ & $\dot{\mathrm{m}}(\mathbf{g} / \mathbf{s})$ & $P($ bar $)$ & $\mathbf{T}(\stackrel{\circ}{ } \mathbf{C})$ & $S(m)$ \\
\hline PA10 & 2.00 & 222 & 38.33 & 0.04 & & 0.3 & 1.17E-02 & 1.0 & 80 & 4.00 \\
\hline PA11 & 2.00 & 256 & 38.33 & 0.04 & & 0.3 & 1.52E-02 & 1.0 & 75 & 2.00 \\
\hline PA12 & 2.00 & 237 & 34.72 & 0.0 & & 0.3 & $1.61 \mathrm{E}-02$ & 1.0 & 72 & 1.00 \\
\hline PA13 & 2.00 & 270 & 34.72 & 0.0 & & 0.3 & 1.49E-02 & 1.0 & 63 & 0.30 \\
\hline \multicolumn{11}{|c|}{ RCA Experimental conditions } \\
\hline \multirow{2}{*}{ TESTS } & Nozzle & \multicolumn{4}{|c|}{ Gas Data } & Aer & rosol Data & \multicolumn{3}{|c|}{ Pool Data } \\
\hline & $D_{N}(\mathrm{~cm})$ & $\mathbf{P}$ (bar) & $\mathbf{T}(\stackrel{\circ}{ } \mathbf{C})$ & $\dot{m}(g / s)$ & $\mathbf{X}_{\mathrm{s}}$ & & $\phi_{\mathrm{p}}(\mu \mathrm{m})$ & $P($ bar $)$ & $\mathbf{T}\left({ }^{\circ} \mathrm{C}\right)$ & $S(m)$ \\
\hline RCA1 & 1.00 & $\approx 2.8$ & 120 & 7.20 & 0.0 & & 3.25 & 2.3 & 120 & 0.25 \\
\hline RCA2 & 1.00 & $\approx 2.8$ & 120 & 7.20 & 0.0 & & 4.02 & 2.3 & 120 & 0.50 \\
\hline $\mathrm{RCA3}$ & 1.00 & $\approx 2.8$ & 120 & 7.20 & 0.0 & & 3.46 & 2.3 & 120 & 1.25 \\
\hline RCA4 & 1.00 & $\approx 2.8$ & 120 & 7.20 & 0.0 & & 4.03 & 2.3 & 120 & 2.50 \\
\hline
\end{tabular}

\subsection{Results and Discussion}

This section presents the analytical calculations results of the SPARC90-Jet code for the experimental data shown in the previous section (Table 2). Additionally, the SPARC90 estimates have been also shown as an indicator of the model enhancement.

Several methods could be used in order to quantitatively take into account the uncertainty sources which are associated with SPARC90-Jet code. The statistic of order method (Wilks, 1941), which is widely extended, has been the selection made in this paper. According to ASME (ASME; 2009) three main uncertainty sources exist in a code, these are: model uncertainties (mainly related with geometry and modelling assumptions, constants, coefficients or empirical correlations implemented in the model, etc.) input parameters uncertainties (errors associated with geometry, initial and boundary conditions, 
material properties, etc.) and numerical uncertainties (associated with the code numerical solving process, i.e., discretization error, iterative solving of equations, etc.). In the case of SPARC90-Jet code, we have focused on the model uncertainties, due to the fact that errors associated with input parameters and numerical code uncertainties have been shown as of minor importance after an initial analysis. Sensitivity and PIRT (Phenomena Identification Ranking Technique) studies have been carried out, these techniques have shown that model expressions related with entrained droplets (entrainment fraction, diameter and velocity) and aerosol capture by inertial impaction are the ones of major importance. Applying to them the Wilks methodology (Wilks, 1941; Wald, 1943), i.e., performing 93 random simulations for each test (all the key expressions vary randomly between their maximum and minimum values, these extreme values were estimated during the sensitivity and PIRT analysis, taking into account of the information available from the literature and estimations based on national laboratory sources). After all this procedure a confidence interval for the output variable under study, DF, has been determined (Table 2).

Table 2. Summary of the experimental DF results and the obtained with SPARC90 and SPARC90-Jet codes

\begin{tabular}{|c|c|c|c|c|c|c|c|c|c|}
\hline & & & Experimen & tal DF & & & SPAF & C90-Jet I & \\
\hline & TEST & Aerosol & min.-max. & Mean & DF & Jet & $\begin{array}{l}\text { Rising } \\
\text { Plume }\end{array}$ & TOTAL & $\begin{array}{l}\text { Uncertainty } \\
\text { min.-max. }\end{array}$ \\
\hline & & Cs & $145.0-160.0$ & & & & & & \\
\hline & AA1 & $\mathrm{Mn}$ & $12.0-33.0$ & $58.12^{*}$ & 14.70 & 2.198 & 13.84 & $30.41^{*}$ & $\begin{array}{l}27.21- \\
3322^{*}\end{array}$ \\
\hline س & & I & $47.0-80.0$ & & & & & & \\
\hline 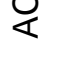 & & Cs & $320.0-330.0$ & & & & & & \\
\hline & AA3 & $\mathrm{Mn}$ & $75.0-140.0$ & $157.0^{*}$ & 33.23 & 2.315 & 30.60 & $70.83^{*}$ & $61.61-75.0^{*}$ \\
\hline & & I & $180.0-220.0$ & & & & & & \\
\hline 山 & $\begin{array}{c}\text { RT-SC- } \\
01 / 02\end{array}$ & Csl & $116.0-128.0$ & 122.0 & 9.50 & 14.33 & 11.32 & 162.2 & $119.1-229.6$ \\
\hline 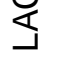 & $\begin{array}{l}\text { RT-SC- } \\
\text { P/01 }\end{array}$ & Csl & $491.0-526.0$ & 508.5 & 21.90 & 14.10 & 32.63 & 460.2 & $338.5-650.1$ \\
\hline$\overline{\bar{z}}$ & PA10 & $\mathrm{SnO}_{2}$ & $8.22-12.98$ & 10.60 & 1.196 & 6.174 & 1.173 & 7.242 & $5.738-8.793$ \\
\hline Оิ & PA11 & $\mathrm{SnO}_{2}$ & $3.95-6.75$ & 5.35 & 1.150 & 4.190 & 1.081 & 4.529 & $4.028-5.636$ \\
\hline $\bar{W}$ & PA12 & $\mathrm{SnO}_{2}$ & $2.80-4.04$ & 3.42 & 1.055 & 3.909 & 1.033 & 4.038 & $3.407-4.834$ \\
\hline O & PA13 & $\mathrm{SnO}_{2}$ & $1.94-3.24$ & 2.59 & 1.026 & 2.599 & 1.006 & 2.615 & $2.326-2.832$ \\
\hline & RCA1 & $\mathrm{Ni}$ & $12.4-13.2$ & 12.80 & 10.33 & 11.24 & 1.246 & 14.00 & $10.41-18.18$ \\
\hline$\varangle$ & $\mathrm{RCA} 2$ & $\mathrm{Ni}$ & $16.0-40.5$ & 28.25 & 11.73 & 11.91 & 2.148 & 25.58 & $20.96-38.24$ \\
\hline O্ & RCA3 & $\mathrm{Ni}$ & $46.6-80.0$ & 63.30 & 13.72 & 13.01 & 5.692 & 74.06 & 55.43-100.4 \\
\hline & RCA4 & $\mathrm{Ni}$ & $\begin{array}{c}719.0- \\
1220.7\end{array}$ & 969.9 & 25.72 & 22.03 & 16.35 & 360.2 & $246.8-504.3$ \\
\hline
\end{tabular}

${ }^{*}$ Weighted with the aerosol composition at the nozzle exit

As can be observed from Table 2, the experimental trends are captured by the SPARC90 and SPARC90-Jet codes. However, there are apparently significant differences in some cases that will be discussed below. As for the SPARC90-Jet and SPARC90 comparisons, it is noticeable that SPARC90-Jet version provides significantly better results for all the tests. 
When SPARC90-Jet estimates are compared to data in terms of collection efficiency (Figure 9), one can notice that differences in DFs are certainly negligible in terms of mass retention efficiency.

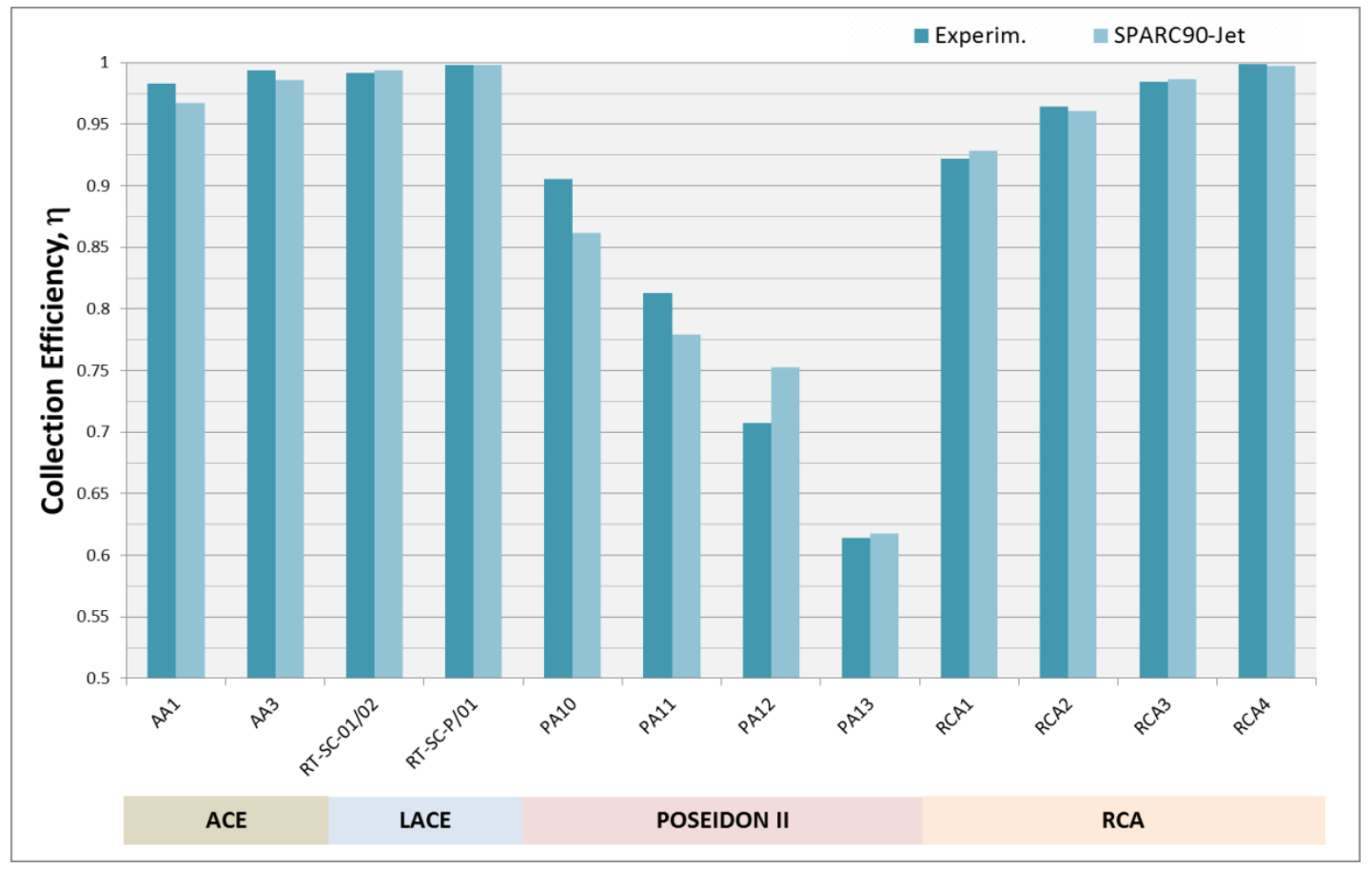

Figure 9. Experimental Collection Efficiency against SPARC90-Jet results

Regarding to DF dependency with test inlet variables and boundary conditions of the studied tests, say that, aerosol sizes and pool depth are of vital importance. Particle size is considered to be a factor of major influence on DF values, an increase in particle size conduces to an increase in the DF. Digging deeper in the dependency of DF with aerosol size, this increasing tendency is clearly shown in LACE experimental data (Figure 10). Both experiments took place in almost the same conditions, the only significant difference was the aerosol size distribution. As can be seen in the figure, smaller aerosol distributions give as a result smaller DFs (tests RT-SC-01/02, $\phi_{p}=1.7 \mu \mathrm{m}$ versus RT-SC-P/01, $\left.\phi_{p}=5.6 \mu \mathrm{m}\right)$. This tendency is clearly shown in the experimental data, being very well captured by the SPARC90-Jet version, but being not well captured in the old version of SPARC90. Consequently, an important advance has been reached in the present improvement of the code. This trend is confirmed by the lower submergence tests (i.e., PA13, RCA1 and RCA2), which are shown in Figure 11, the contribution of jet and rising plume regions to the DF have been displayed separately, along with the total DF and the experimental data, from this figure it can be said that higher values of DF are reached for larger sizes of aerosols in both regions. Even though, in the rising plume there is not virtually decontamination $(D F \approx 1)$, having only a slight increasing slope with aerosol sizes. 


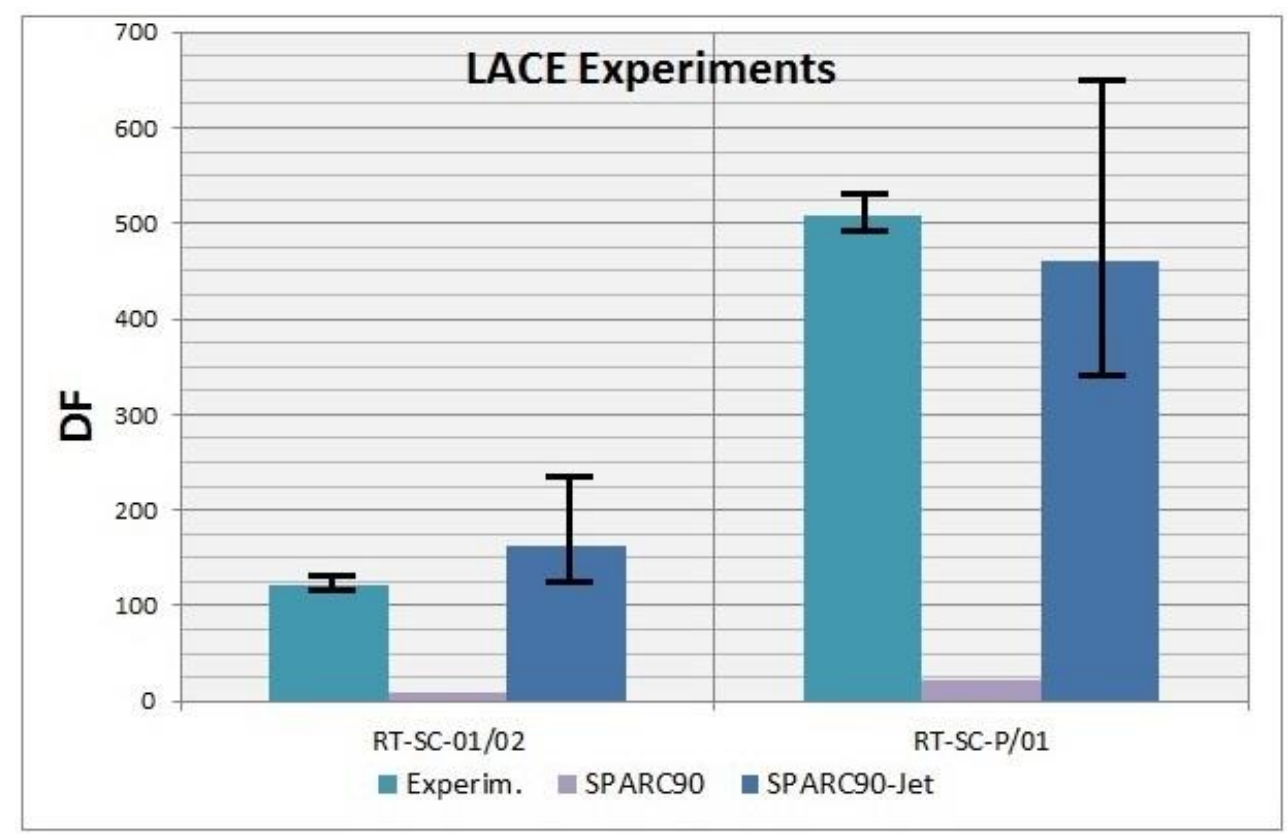

Figure 10. DF experimental data and results of SPARC90 and SPARC90-Jet codes for LACE experiments

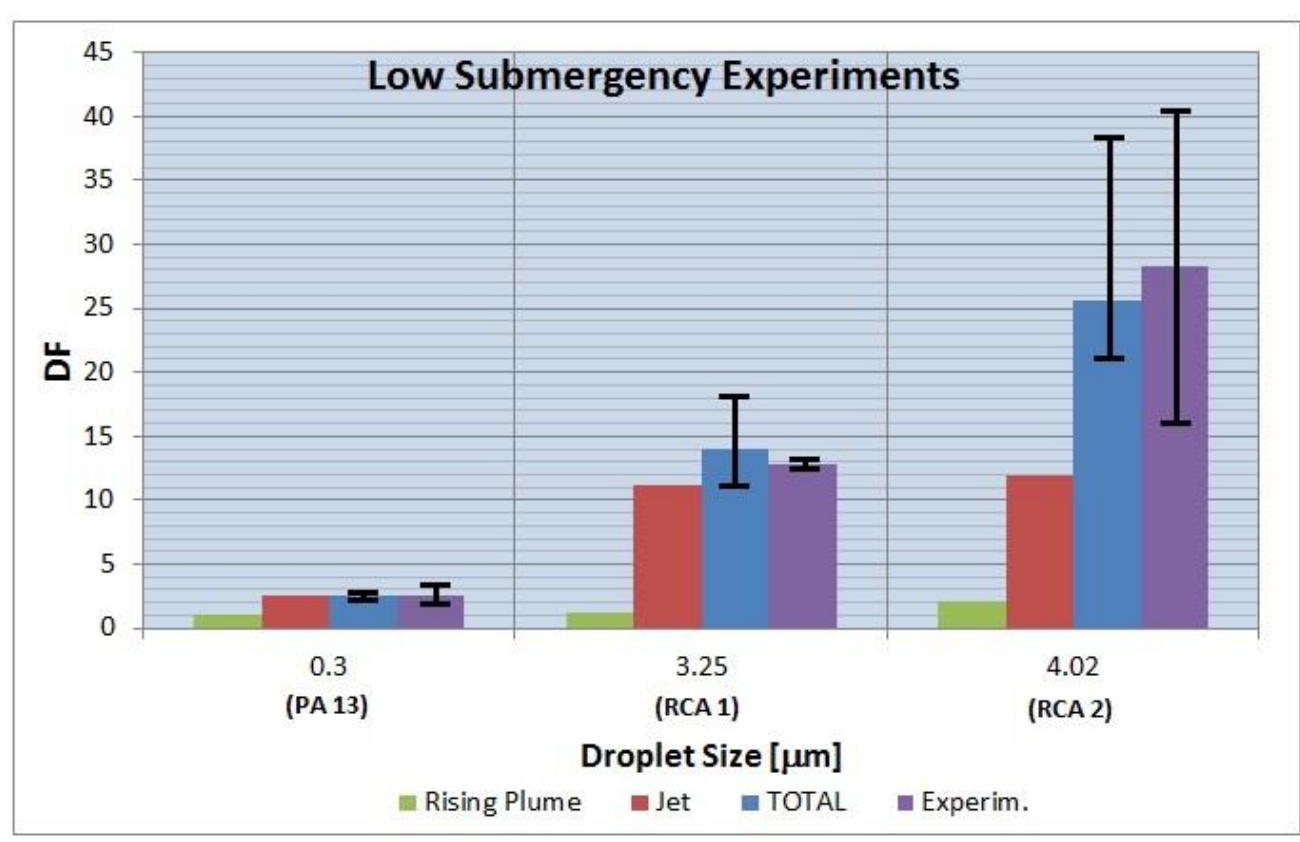

Figure 11. Experimental data vs SPARC90-Jet results (Total, Jet and Rising Plume regions) of the DF for the low submergency experiments

The pool depth, submergency, is another key variable to take into account to determine the DF, as it is shown in Figures 12 and 13. The four POSEIDON II experiments studied here (Figure 12) took place in almost the same conditions (small aerosol size $\approx 0.3 \mu \mathrm{m}$, high jet and pool temperatures $\approx 250-$ $75{ }^{\circ} \mathrm{C}$ respectively, with a low fraction or cero condensable gases and pressures near the atmospheric values), apart from submergency, which varies from 4.0 to 0.3 meters in the four experiments (PA10 - $4.0 \mathrm{~m}, \mathrm{PA} 11-2.0 \mathrm{~m}$, PA12 - $1.0 \mathrm{~m}$ and PA13 $-0.3 \mathrm{~m}$ ). The upward trend of DF values with the increase of pool depth, which is seen in the experimental data, is quite well captured by the new code version. While for the old version, the DF values 
remain almost constant along all tests (only a very small upward tendency). This increasing tendency of DF values with submergency is due to the fact that the height of water above the injector determines the residence time of the aerosols.

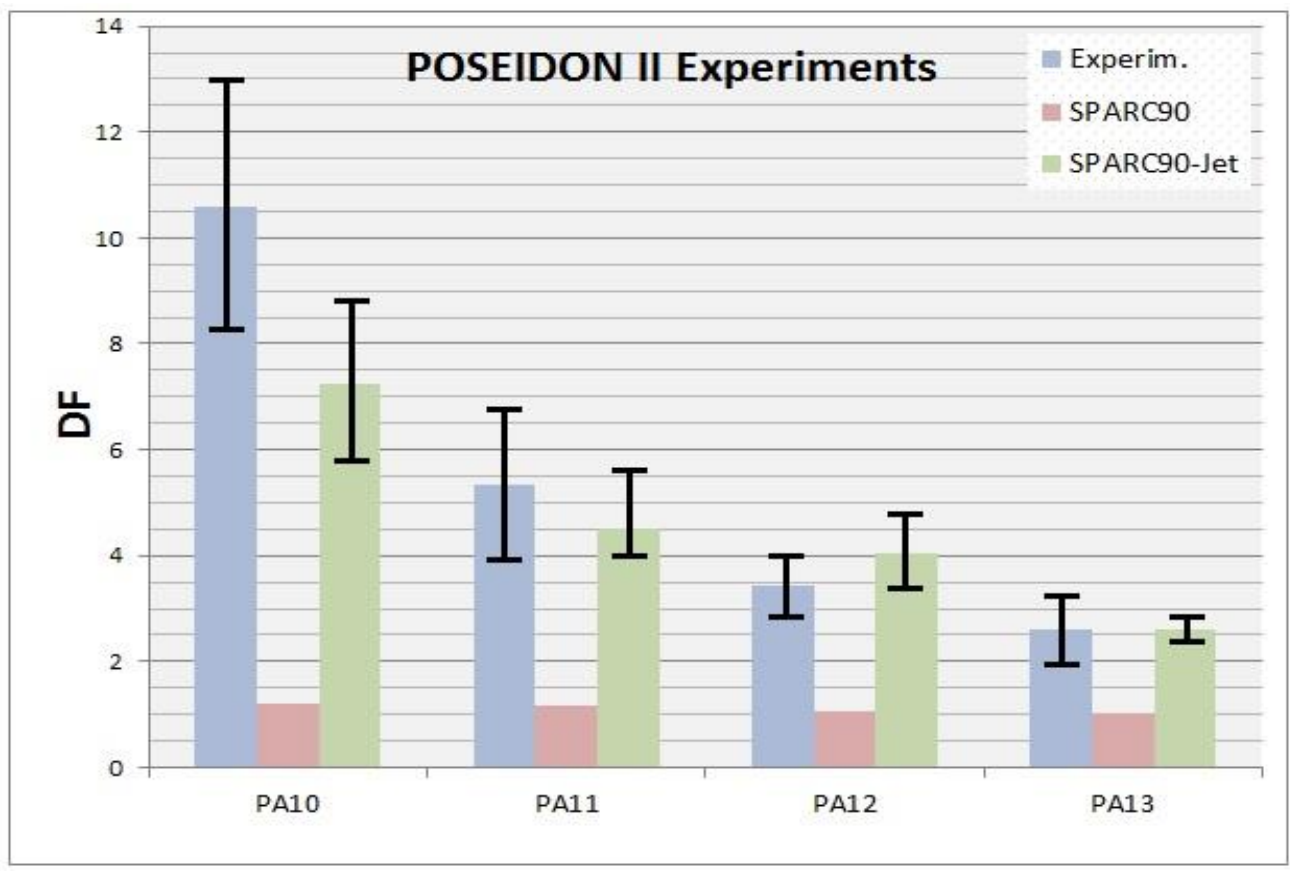

Figure 12. DF experimental data and results of SPARC90 and SPARC90-Jet codes for POSEIDON II experiments

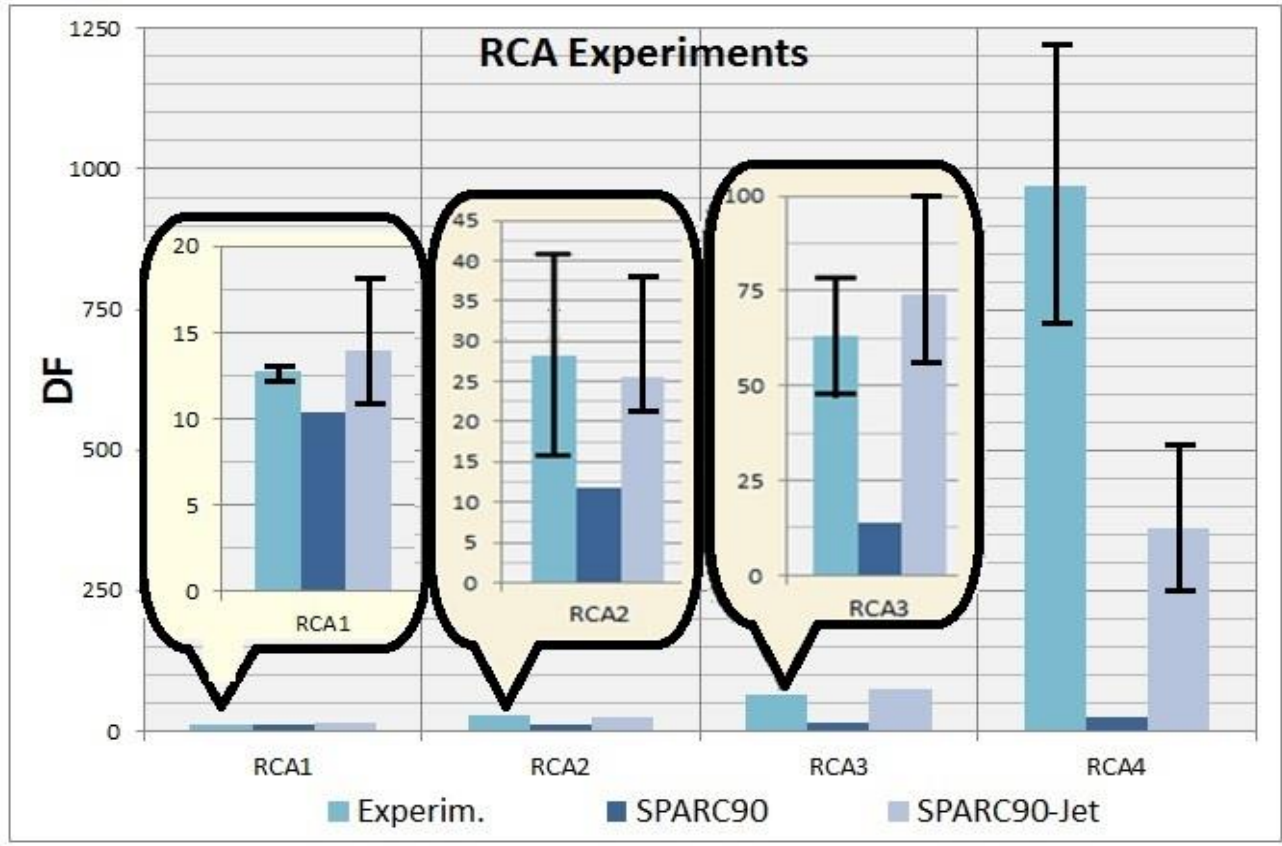

Figure 13. DF experimental data and results of SPARC90 and SPARC90-Jet codes for RCA experiments

The same conclusion as the expressed in the previous paragraph can be extracted from the four RCA experiments (Figure 13), even though in this case the aerosol sizes and pool and jet pressures were higher than in POSEIDON II experiments (aerosol sizes $\approx 4.0 \mu \mathrm{m}$., jet and pool pressures $\approx 2.8-2.3$ bars 
respectively). We must highlight the fact that $D F$ has a significantly higher value in RCA experiments than in POSEIDON II experiments, this results is mainly caused by the higher aerosol size (this statement will be discussed in next paragraphs). The confirmation of the assertion made earlier, increasing DF with pool depth, can be clearly seen in Figure 12 (RCA1 - $0.25 \mathrm{~m}$, RCA2 - $0.5 \mathrm{~m}$, RCA3 $-1.25 \mathrm{~m}$ and RCA4 - $2.5 \mathrm{~m}$ ).

It seems intuitive to believe that, aerosol capture processes caused by changes in submergency, mainly or only take place in the rising plume. But if Figure 14 is seen, in which the contributions of the rising plume and jet regions for RCA experiments have been broken down, it is observed that the effect of submergence is seen in both regions. While it is true that this effect is observed in a more pronounced way in the rising plume region. But what it is most surprising, for POSEIDON II experiments, there is an increasing tendency with submergence, but this is not caused by the rising plume region (which is true that has a very slight upward trend), but for the jet region, as seen in Figure 15. This situation might be caused by the aerosol sizes, small ones have very small collection efficiency in the rising plume but still significant in the jet region.

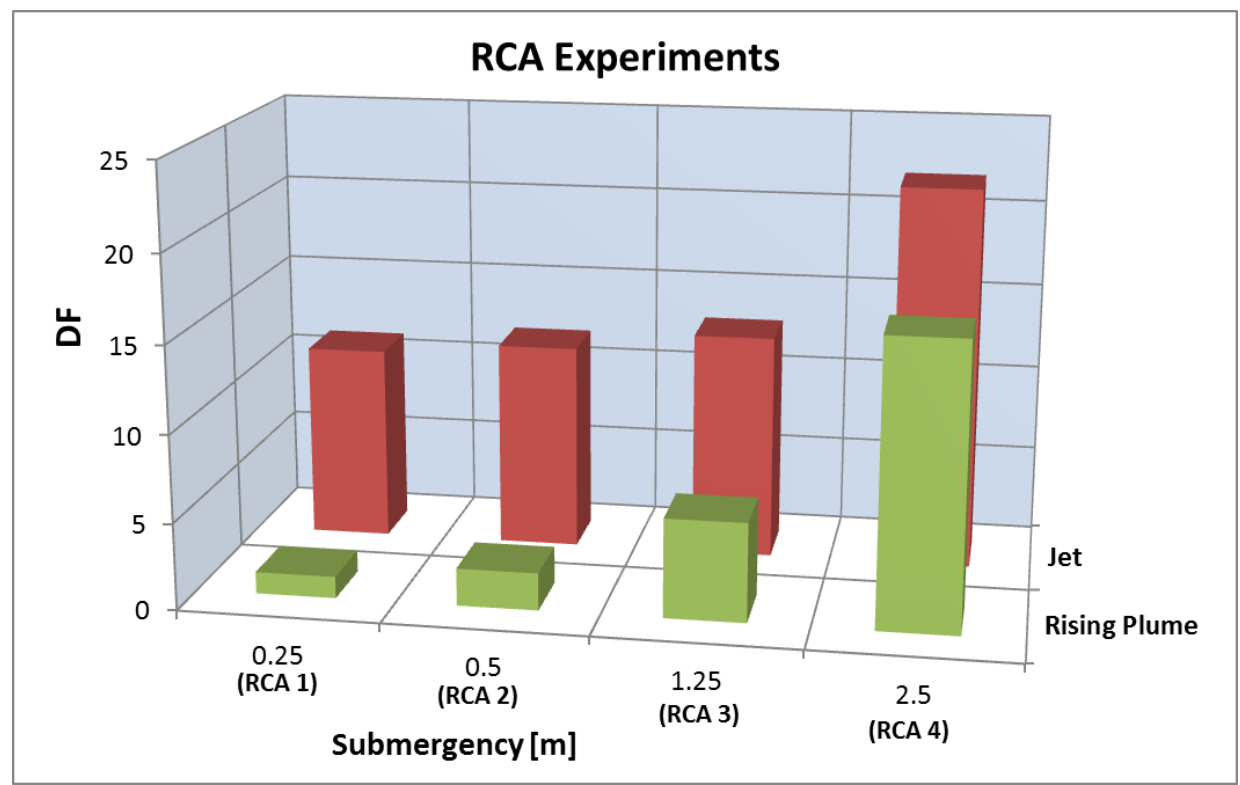

Figure 14. Contributions of the Injection and Rising Plume regions to the DF for RCA experiments according to SPARC90-Jet code 


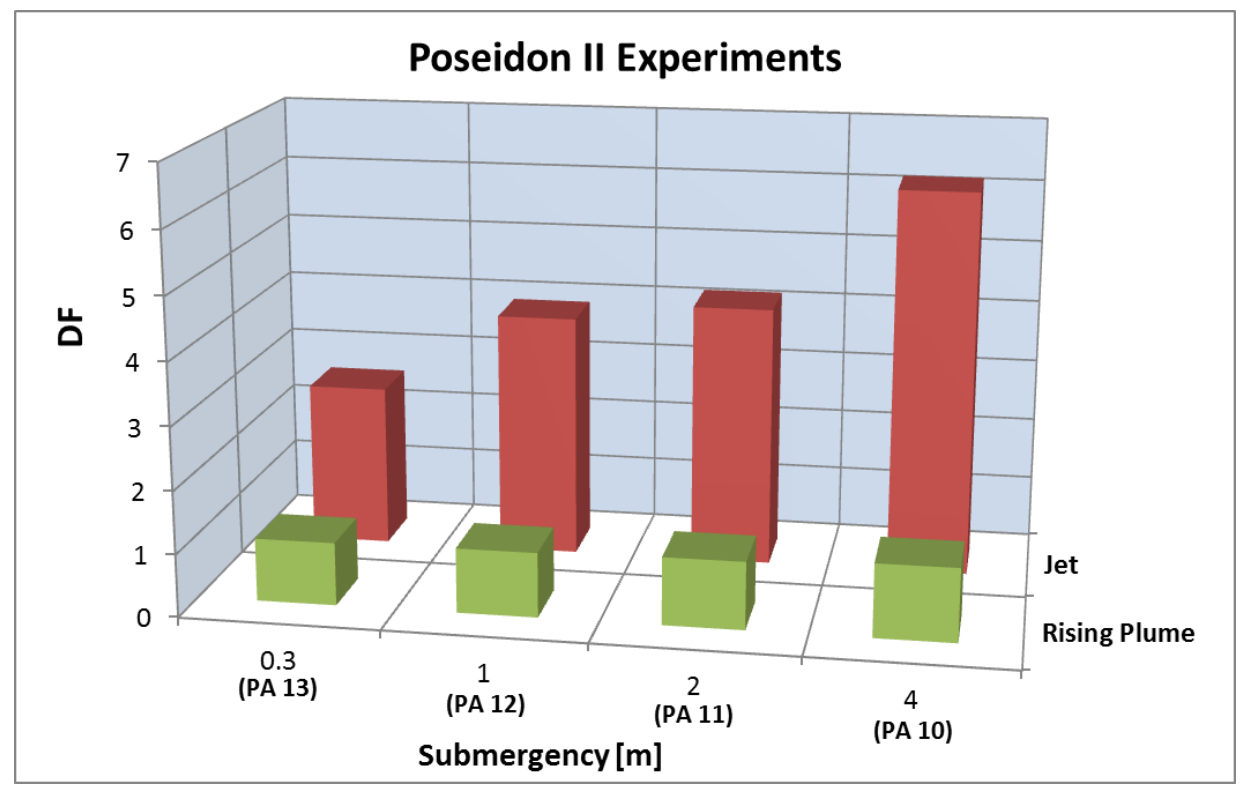

Figure 15. Contributions of the Injection and Rising Plume regions to the DF for POSEIDON II experiments according to SPARC90-Jet code

Figure 16 shows the results of ACE experiments. In this case the experimental conditions of both experiments were quite different (submergency 1.38 - $2.62 \mathrm{~m}$, gas and pool temperatures $138-150{ }^{\circ} \mathrm{C}$ and $26-82{ }^{\circ} \mathrm{C}$ respectively for AA1 and AA3 tests) and added to these different experimental conditions there was a mixture of aerosols ( $\mathrm{MnO}, \mathrm{CsOH}$ and $\mathrm{Csl})$. So many effects were combined to give as a result an experimental DF for each case. But despite this complexity, there are satisfactory results with the new version of the code, which improve significantly those of the old version, even though the predicted DF's are significantly lower.

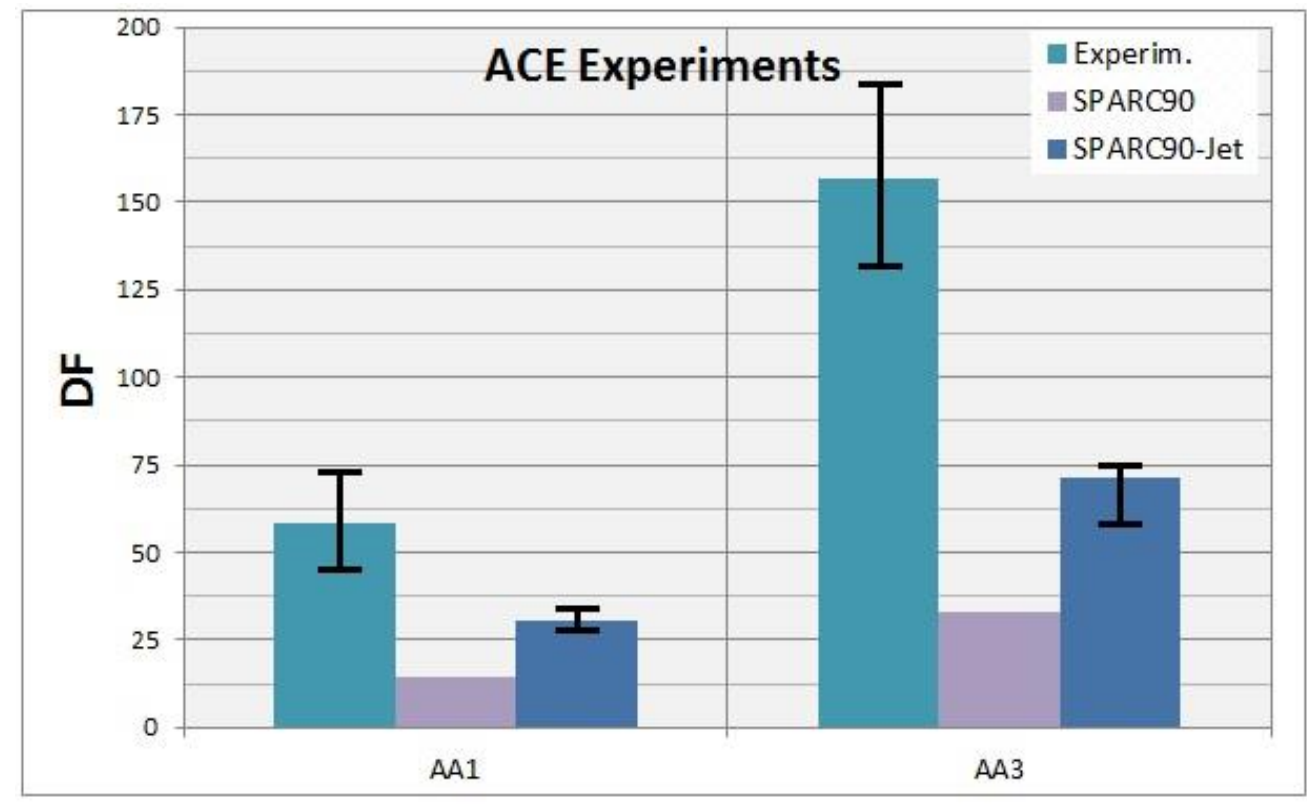

Figure 16. DF experimental data and results of SPARC90 and SPARC90-Jet codes for ACE experiments

Finally, to close up this section of confrontation of SPARC90-Jet code with his old version and against the experimental data, we must highlight that SPARC90-Jet provides much better results than his previous version, being 
closer to the experimental data for all the studied tests, despite the fact that in certain tests the error bars of the experimental data and the calculations of the SPARC90-Jet code does not overlap. Although, remind once again that the old SPARC90 code version was not intended for jet discharge processes, but only for globular discharges, so it is not surprising the poor results of the old version in the majority of the experimental tests under study. And we conclude that the main effects on DF are the injection pressure (either directly or through the submergence) and the aerosol sizes, having both of them an upward tendency, i.e. higher values of these variables gives as a results higher values of DF. But further investigations are needed to confirm these conclusions and to try to capture new trends dependent with other input variables.

\section{FINAL REMARKS AND FURTHER WORK}

As it is well known, submerged jet hydrodynamics might have an outstanding implication in the eventual attenuation of radioactivity release from nuclear power plant accidents, particularly in Steam Generator Tube Rupture accidents (SGTR accident) for PWRs and Station Black-Out (SBO events) in BWRs. Despite this relevance of gas-liquid interactions in submerged gas jet very little information is available in the open literature. Throughout this paper the major features of a model built-up on existing equations and own assumptions called SPARC90-Jet have been outlined.

This new version of the SPARC90 code is focused on high gas velocity injection regime. The development of the new code has been done by choosing up-to-date equations from the open literature, jet hydrodynamics has been modeled and suitable aerosol equations have been adopted.

The theoretical results offered by the SPARC90-Jet code have been compared with four experimental programs, allowing the validation of the models and strengthening its reliability. This confrontation has been satisfactory, as it has been shown in the previous section, the experimental data and the simulations follow the same trends. We must highlight some major insights, such as the capability of SPARC90-Jet to capture the increasing DF with aerosol diameter and with pressure-submergency, catching not only the experimental trend but also the magnitude. Finally, emphasize the substantial improvement achieved with regard to the old SPARC90 code version, which has been clearly shown when comparing the SPARC90 and the SPARC90-Jet results against the available experimental data. All the previously comments have been said with caution due to the model developed so far should be considered as preliminary and subject to improvements in several areas, added to the need to compare against a more extensive experimental database. Though, the results are encouraging, as the experimental trends are quite well captured, the final goal has not been reached yet.

In short, despite the promising performance of the SPARC90-Jet model, it should be seen just as a step forward in the modeling of scrubbing under jet injection regime. There are still many aspects of SPARC90-Jet still susceptible to be improved, either because they rely on assumptions which need of further confirmation, on user experience and on own experimental results which are under analysis or because the available experimental data for the validation started in this paper is not as extensive as desirable. As a matter of fact, this is 
the key issue to develop further any model of jet injection scrubbing, data scarcity. So experimentation is of vital importance, so as to have expressions specifically developed for submerged jets and to have a larger database against which compare the code results.

\section{ACKNOWLEDGMENTS}

The authors are indebted to the financial support of MODEXFLAT project, reference: ENE2013-48565-C2-1-P. 


\section{NOMENCLATURE}

$\begin{array}{ll}\text { BWR } & \text { Boling Water Reactor } \\ \mathrm{C} & \text { Wave celerity } \\ \mathrm{C}_{0} & \text { Speed of sound } \\ \mathrm{C}_{\mathrm{c}} & \text { Cunningham slip-correction factor } \\ \mathrm{C}_{\alpha} & \text { Energy flow correction coefficient } \\ \mathrm{C}_{\beta} & \text { Pulsating motions correction coefficient } \\ \mathrm{C}_{\mathrm{p}} & \text { Particles mass concentration } \\ \mathrm{C}_{W} & \text { Surface tension factor } \\ \mathrm{D} & \text { Gas jet diameter } \\ \mathrm{D}_{\text {diff }} & \text { Diffusion coefficient } \\ \mathrm{D}_{\mathrm{N}} & \text { Nozzle diameter } \\ \mathrm{DF} & \text { Decontamination Factor } \\ \mathrm{E} & \text { Entrained droplet fraction } \\ \mathrm{Fr} & \text { Froude number } \\ \mathrm{f}_{\mathrm{gi}} & \text { Gas interfacial friction factor } \\ \mathrm{g} & \text { Gravity acceleration } \\ \mathrm{k} & \text { Stephan-Boltzmann constant } \\ \mathrm{Ku} & \text { Kutateladze number } \\ \mathrm{L}_{\text {jet }} & \text { Jet penetration lenght } \\ \mathrm{I}_{\mathrm{c}} & \text { Droplet lenght scale } \\ \mathrm{LWR} & \text { Light Water Reactor } \\ \mathrm{m} & \text { Mass } \\ \dot{\mathrm{m}}, \mathrm{M} & \text { Mass flow rate } \\ \mathrm{N}_{\mathrm{d}} & \text { Droplet concentration } \\ \mathrm{N}_{\mu} & \text { Viscosity number } \\ \mathrm{Oh} & \text { Ohnesorge Number } \\ \mathrm{P} & \text { Pressure } \\ \mathrm{Pe} & \text { Peclet number } \\ \mathrm{PIRT} & \text { Phenomena Identification Ranking Technique } \\ \mathrm{PWR} & \text { Pressurized Water Reactor } \\ \mathrm{r} & \text { Radius } \\ \mathrm{R} & \text { Gas jet radius } \\ \mathrm{Re} & \text { Reynolds number } \\ \mathrm{S} & \text { Submergency } \\ \mathrm{SBO} & \text { Station Black-Out } \\ \mathrm{SG} & \text { Steam Generator } \\ \mathrm{SGTR} & \text { Steam Generator Tube Rupture } \\ \mathrm{SPARC} & \text { Suppression Pool Aerosol Removal Code } \\ \mathrm{Stk} & \text { Stokes number } \\ \mathrm{T} & \text { Temperature } \\ \mathrm{u} & \text { Fluid velocity } \\ \mathrm{V} & \text { Volume } \\ \mathrm{V}_{\mathrm{e}} & \text { Entrainment velocity, Spalding-Ricou model } \\ \mathrm{V}_{\mathrm{inp}} & \text { Entrainment inception velocity } \\ \mathrm{We} & \text { Weber number } \\ \mathrm{X}_{\mathrm{s}} & \text { Steam volume fraction } \\ \mathrm{z} & \text { Axial direction } \\ & \\ & \end{array}$




\begin{tabular}{ll} 
Greek Symbols \\
$\alpha$ & Void fraction \\
$\delta$ & Liquid film thickness \\
$\Delta h_{\mathrm{w}}$ & Wave amplitude \\
$\phi_{\mathrm{d}}$ & Droplet diameter \\
$\phi_{\mathrm{p}}$ & Particle or aerosol diameter \\
$\gamma$ & Isentropic expansion coefficient \\
$\lambda$ & Mean free path \\
$\lambda_{\mathrm{c}, \mathrm{K}-\mathrm{H}}$ & Wavelenght of Kelvin-Helmholtz instability \\
$\eta$ & Collection efficiency \\
$\mu$ & Dynamic viscosity \\
$\theta$ & Jet expansion angle \\
$\rho$ & Density \\
$\sigma$ & Surface tension \\
$\tau_{\text {friction }}$ & Interfacial shear stress \\
Subscripts \\
0 & Initial, at the tube break \\
1 & Final, after the expansion \\
crit & Critical \\
$\mathrm{d}$ & Droplet \\
$\mathrm{ffOE}$ & Liquid film values at the onset of entrainment \\
$\mathrm{g}$ & Gas \\
in & Inlet \\
$\mathrm{j}$ & Droplet class size \\
$\mathrm{k}$ & Aerosol class size \\
$\mathrm{I}$ & Liquid film \\
$\mathrm{max}$ & Maximum \\
$\mathrm{p}$ & Particle or aerosol \\
out & Outlet \\
ref & Reference \\
ret & Retained \\
& \\
\hline
\end{tabular}

\section{REFERENCES}

- ASME, "Standard for verification and validation in computational fluid dynamics and heat transfer", ASME V V 20 (2009).

- Azzopardi, B.J., "Drops in annular two-phase flow". International Journal of Multiphase Flow, Vol. 23, pp. 1-53. (1997).

- Berna, C., Escrivá, A., Muñoz-Cobo, J.L., \& Herranz, L.E., "Pool Scrubbing under Jet Injection Regime: An Enhancement of the SPARC90 Code". Proceedings of ICAPP'12, Chicago, USA (2012).

- Berna, C., Escrivá, A., Muñoz-Cobo, J.L., \& Herranz, L.E., "Review of droplet entrainment in annular flow: interfacial waves and onset of entrainment". Progress in Nuclear. Energy, vol. 74, p.p. 14-43 (2014).

- Berna, C., Escrivá, A., Muñoz-Cobo, J.L., \& Herranz, L.E., "Enhancement of the SPARC90 code capabilities for pool scrubbing under jet injection regimes ". Computational Methods in Multiphase Flow VIII, WIT Press, p.p. 273-285 (2015a). 
- Berna, C., Escrivá, A., Muñoz-Cobo, J.L., \& Herranz, L.E., "Review of droplet entrainment in annular flow: characterization of the entrained droplets". Progress in Nucear. Energy, vol. 79, p.p. 64-86 (2015b).

- Bubnov, V.A., "Turbulent Isentropic Flows". Journal of Engineering and Thermophysics, Vol. 71, p. 334-339 (1998).

- Crowe, C.T., "Multiphase Flow Handbook (Mechanical Engineering)". CRC Press, Taylor and Francis Group (2006).

- Dehbi, A., Suckow, D., \& Güntay, S., "Aerosol Retention in Low-Subcooling Pools under Realistic Accident Conditions". Nuclear Engineering and Design 203, p.p. 229-241 (2001).

- Epstein, M., "Theory of scrubbing of volatile fission product vapour containing gas jet in a water pool". ANS winter meeting, November 11-16 Washington DC (1990).

- Escudero, M., Marcos, M.J., Swiderska-Kowalczyk, M., Martin, M., \& López-Jiménez, J., "State of the art review on fission products aerosol pool scrubbing under severe accident conditions". Nuclear Science and Technology, European Commission Report, EUR 16241 EN (1995).

- Flagan, R.C., \& Seinfeld, J.H., "Fundamentals of Air Pollution Engineering". Prentice Hall (1988).

- Fore, L.B., \& Dukler, A.E., "The distribution of drop size and velocity in gas-liquid annular flow". Int. J. Multiphase Flow 21, pp. 137-149 (1995).

- Herranz, L.E., Fernández, E., López, C. \& Berna, C., "Modeling Hydrodynamics of Submerged Gas Jets under Anticipated Conditions in Severe Nuclear Accidents". $8^{\text {th }}$ International Conference on Multiphase Flow (ICMF 2013), Jeju, Korea (2013).

- Herranz, L.E., Lind, T., Dieschbourg, K., Riera, E., Morandi, S., Rantanen, P., Chebbi, M., \& Losch, N., "Technical Bases for Experimentation on Source Term Mitigation: The EU-PASSAM Project". The 10th International Topical Meeting on Nuclear Thermal-Hydraulics, Operation and Safety (NUTHOS-10), Okinawa, Japan (2014).

- Hinze, J.O., "Fundamentals of the Hydrodynamic Mechanism of Splitting in Dispersion Process". AIChE Journal, Vol. 1 (1955).

- Hoefele E.O. \& Brimacombe J.K. "Flow Regimes in Submerged Gas Injection". Metallurgical Transactions, Vol. 10B, pp. 631-648 (1979).

- Ishii, M., \& Grolmes, M.A., "Inception Criteria for Droplet Entrainment in Two-Phase Concurrent Film Flow". AIChE Journal, Vol. 21 p. 308-318 (1975).

- Jung, C.H., \& Lee, K.W., "Filtration of fine particles by multiple liquid droplet and gas bubble systems". Aerosol Science and Technology, Vol. 29, pp. 389-401 (1998).

- Kataoka, I., Ishii, M., \& Nakayama, A., "Entrainment and deposition rates of droplets in annular two-phase flow". Int. J. Heat Mass Transf. 43, 1573-1589 (2000).

- Kolev, N.I., "Multiphase Flow Dynamics: Thermal and Mechanical Interactions". Springer Science \& Business Media, $3^{\text {th }}$ Edition (2007).

- López-Jiménez, J., Herranz, L.E., Escudero, M.J., Espigares, M.M., Peyrés, V., Polo, J., Kortz, Ch., Koch, M.K., Brockmeier, U., Unger, H., Dutton, L.M.C., Smedley, Ch., Trow, W., Jones, A.V., Bonanni, E., Calvo, M. \& Alonso, A., "Pool scrubbing". Informes Técnicos Ciemat, $\mathrm{N}^{\mathrm{er}} 805$ (1996).

- Mantilla, I., "Mechanistic Modeling of Liquid Entrainment in Gas in Horizontal Pipes". PhD. Thesis University of Tulsa (2008).

- Owczarski, P.C., Scherck, R.I., \& Postma, A.K., "Technical Bases and User's Manual for the Prototype of a Suppression Pool Aerosol Removal Code (SPARC)", U. S. Nuclear Regulatory Commission, NUREG/CR-3317 PNL-4742 R1 (1985).

- Owczarski, P.C., \& Burk, K.W., "SPARC-90: A Code for Calculating Fission Product Capture in Suppression Pools", U. S. Nuclear Regulatory Commission, NUREG/CR5765 TI92 003256 (1991).

- Owen, D.G., \& Hewitt, G.F., "An improved annular two-phase flow model”. Proceedings of the Third International Conference on Multiphase Flow, Hague, Netherlands (1987).

- Ramsdale, S., Friederichs, H-G., \& Güntay, S., "BUSCA JUN91: Reference Manual for the Calculation of Radionuclide Scrubbing in Water Pools". ISBN 3923875665, GRS (1991).

- Ricou, F.B., \& Spalding, D.B., "Measurements of Entrainment by Axisymmetrical Turbulent Jets", Journal of Fluid Mechanics, Vol. 11, p.p. 21-32 (1961). 
- Someya, S., Uchida, M, Li, Y., Ohshima, H., \& Okamoto, K., "Entrained droplets in underexpanded gas jet in water". Journal of Visualization, DOI 10.1007/s12650-0110089-7 (2011).

- Spore, J.W., Elson, J.S., Jolly-Woodruff S.J., Knight T.D., Lin J.-C., Nelson, R.A., Pasamehmetoglu K.O., Steinke R.G., Unal, C., Mahaffy J.H., \& Murray, C., "TRACM/FORTRAN 90 (Version 3.0) Theory Manual”. LA-UR-00-910 July 2000.

- Wassel, A.T., Mills, A.F., \& Bugby, D.C., "Analysis of radionuclide retention in water pools". Nuclear Engineering and Design 90(87), 1985.

- Wald, A., "An extension of Wilks' method for setting tolerance limits", Annals of Mathematical Statistics, vol. 14, no 1, p.p. 45-55 (1943).

- Wilks, S.S., "Determination of sample sizes for setting tolerance limits", Annals of Mathematical Statistics, vol. 12, $n^{\circ}$ 1, p.p. 91-96 (1941).

- Yecko, P., "Viscous modes in two-phase mixing layers". Physics of Fluid, Vol. 14, p.p. 4115-4121 (2002).

- Zhao, H., \& Zheng, C., "Modeling of Gravitational Wet Scrubbers with Electrostatic Enhancement" Chemical Engineering Technology, Vol. 31, No 12, p.p. 1824-1837 (2008). 